\title{
On Kincaidiana Altman, 1936 and Guestphalinus Michaelsen, 1933 (Annelida, Clitellata, Lumbriculidae), with the descriptions of three new species
}

\author{
Steven V. FEND ${ }^{1,{ }^{*}}$, Pilar RODRIGUEZ ${ }^{2}$, Ainara ACHURRA ${ }^{3}$ \& Christer ERSÉUS $^{4}$ \\ ${ }^{1}$ US Geological Survey, 345 Middlefield Rd., Menlo Park, CA, 94025, USA. \\ ${ }^{2,3}$ University of the Basque Country, UPV/EHU, Sarriena s/n, Leioa 48940, Spain. \\ ${ }^{4}$ University of Gothenburg, SE-405 30 Göteborg, Sweden. \\ *Corresponding author: svfend@usgs.gov \\ ${ }^{2}$ Email: pilar.rodriguez@ehu.eus \\ ${ }^{3}$ Email: ainara.achurra@ehu.eus \\ ${ }^{4}$ Email: christer.erseus@bioenv.gu.se \\ ${ }^{1}$ urn:Isid:zoobank.org:author:E0C611FA-9619-4DFD-9701-026417181232 \\ ${ }^{2}$ urn:1sid:zoobank.org:author:C4600D2B-17E2-4CD0-AE75-B79BA9DD35D6 \\ ${ }^{3}$ urn:Isid:zoobank.org:author:105572EB-B070-4BE4-93D2-50FA50847C9E \\ ${ }^{4}$ urn:lsid:zoobank.org:author:D98F606A-B273-4F50-95F5-C35F17B12C85
}

\begin{abstract}
Two formerly monotypic lumbriculid genera, Guestphalinus Michaelsen, 1933 and Kincaidiana Altman, 1936, are reviewed using morphological and molecular data, following the discovery of new northwestern, Nearctic species. Several populations of Kincaidiana hexatheca Altman, 1936 were examined, and both morphology and DNA data suggest a single, variable species in Pacific drainages extending from northern California through Washington, USA. Specimens of Kincaidiana from the Smith River drainage with a single, median atrium and differing genetically from $K$. hexatheca are assigned to K. smithi sp. nov. The chaetal morphology of North American Guestphalinus populations is variable, and two basic morphotypes are assigned to G. elephantinus sp. nov. and G. exilis sp. nov. This decision is supported by molecular data. The tree topology, based on the mitochondrial $16 \mathrm{~S}$ rRNA and Cytochrome Oxidase I (COI), and the nuclear 28S rRNA gene sequences, confirmed the close phylogenetic relationships among the Nearctic Guestphalinus, Kincaidiana and Uktena Fend, Rodriguez \& Lenat, 2015. Probable synapomorphies associating these genera include a filiform, ringed proboscis, a forward shift of reproductive organs relative to the usual position in the family, and spermathecae in the atrial segment.
\end{abstract}

Keywords. Taxonomy, new taxa, Clitellata, Lumbriculidae, Kincaidiana, Guestphalinus.

Fend S.V., Rodriguez P., Achurra A. \& Erséus C. 2017. On Kincaidiana Altman, 1936 and Guestphalinus Michaelsen, 1933 (Annelida, Clitellata, Lumbriculidae), with the descriptions of three new species. European Journal of Taxonomy 361: 1-46. https://doi.org/10.5852/ejt.2017.361 


\section{Introduction}

Recent worm collections from northwestern USA have yielded many specimens of large, proboscisbearing lumbriculids with spermathecae in the atrial segment (a character uncommon within the family), and atria in a segment anterior to $\mathrm{X}$ (the most common position in the family). Thus, these distinctive worms show affinities with the genera Guestphalinus Michaelsen, 1933, Kincaidiana Altman, 1936 and Uktena Fend et al., 2015.

The European Dorydrilus (Guestphalinus) wiardi Michaelsen, 1933, later transferred to the monotypic genus Guestphalinus by Hrabě (1936), was originally known from caves in Germany and had a unique combination of characters: semiprosoporous male ducts (atria with both anterior and posterior vasa deferentia), atria in IX, and paired spermathecae only in the atrial segment. Soon afterward, the genus Kincaidiana was designated for $K$. hexatheca Altman, 1936, a distinctive lumbriculid from western North America. Kincaidiana hexatheca, also with atria in IX, differed from G. wiardi in having prosoporous male ducts (each atrium with only posterior vas deferens) and spermathecae paired in three segments, IX-XI. Other defining characters of $K$. hexatheca included bifid chaetae in some anterior segments, and highly branched lateral blood vessels. More recently, Fend et al. (2015) described the monotypic Uktena riparia Fend, Rodriguez \& Lenat, 2015 from southeastern USA. Like $K$. hexatheca, it had prosopore male ducts, and like Guestphalinus, spermathecae were restricted to a single pair in the atrial segment. However, the location of atria in VIII, and other diagnostic characters, such as large spermatophores and numerous copulatory chaetae, were unique to Uktena within the family Lumbriculidae.

In this paper, we describe and incorporate new collections of North American worms associated with the above taxa. Two new Guestphalinus species are described herein, based on both morphological and molecular data, and their morphology is compared with specimens of G. wiardi from two sites in southern Europe. Kincaidiana hexatheca, which has been reported in a variety of habitats in Pacific Coastal watersheds from northern California to southern British Columbia (Altman 1936; Cook 1971; Brinkhurst 1976; Fend 2009), shows considerable intra- and inter-population differences in size and other morphological details that will be examined here. The most unusual Kincaidiana population, collected from northern California, has a single, median male pore and atrium. This morphotype is here attributed to a new species, Kincaidiana smithi sp. nov., and is supported by molecular evidence. Phylogenetic relationships among these genera are also discussed on the basis of morphology and available molecular data.

\section{Material and methods}

Streams were sampled from both erosional and depositional habitats in northwestern U.S.A. (the states of Washington, Oregon, and California), using a $500 \mu \mathrm{m}$ mesh dip net. In riffle habitats, worms were usually found by disturbing patches of finer gravel to a depth of about $20 \mathrm{~cm}$. More depositional habitats in streams, as well as small seeps and pools, were generally sampled by sieving silt and organic detritus with a $500 \mu \mathrm{m}$ screen. Some Kincaidiana hexatheca were collected by digging in saturated riparian mud. Most specimens were relaxed in dilute ethanol and fixed in formalin-aceto-alcohol for morphological study, or in $80-90 \%$ ethanol for DNA. Specific conductance was measured at a few sites in April, 2014, using a Cole Parmer model 1481-80 conductivity meter.

Most specimens used for morphological study were stained in either hematoxylin or borax carmine, partially destained in acidified alcohol, longitudinally dissected, dehydrated in an alcohol series, cleared in methyl salicylate, and mounted in Canada balsam. Sagittal sections were cut at $7 \mu \mathrm{m}$, transverse sections at $10 \mu \mathrm{m}$. All sections were stained in hematoxylin and eosin. The descriptions of reproductive structures are based on mature specimens, with sperm in the spermathecae, and usually with well-developed eggs. Characteristics of "nearly-mature" worms (e.g., atria and spermathecae appear incompletely developed, or without sperm in sperm funnels and spermathecae) and "post-reproductive" worms (e.g., some 
resorption of reproductive organs, sperm sacs and egg sacs almost empty, spermathecae without darklystaining sperm) are described in some cases. Measurements of chaetae are based on slide-mounted worms, but body lengths and widths were supplemented with measurements obtained from unmounted worms in alcohol; unless otherwise noted, measurements of somatic characters were based on specimens with at least partially-developed reproductive pores. Measurements are given as ranges, or as a range followed by the median value in parentheses. Segment numbers are indicated by Roman numerals; intersegments by Arabic numerals (as 9/10 to indicate the septum between IX and X). To simplify the descriptions, we use the general spatial terms "ental vs ectal" (internal vs body wall) for the orientation of internal organs having external pores. For description of chaetae we have used the terms "proximal/ distal", which refer to the distance to the anchor point in the body wall.

Posterior parts of selected specimens (Table 1) were cut and transferred into 95\% ethanol for the molecular analyses; anterior parts were treated following the procedures described above and identified to species level. DNA from tissue of posterior parts was extracted using the DNAeasy Tissue Kit (Qiagen) or the QuickExtract DNA Extraction Solution 1.0 from Epicentre (following instructions from the manufacturer). We used primers LCO1490 and HCO2198 (Folmer et al. 1994) or COI-E (Bely \& Wray 2004) for COI, 16SAR-L and 16SBRH (Palumbi et al. 1991) for 16S and 28SC1 and 28SC2 (Dayrat et al. 2001) for the 28S rRNA. Each PCR reaction consisted of $21 \mu 1 \mathrm{ddH} 2 \mathrm{O}, 1 \mu 1$ of each primer $(10 \mu \mathrm{M}), 2 \mu \mathrm{l}$ template DNA and Illustra PuReTaq Ready-To-Go PCR Beads $(0.2 \mathrm{ml}$ tubes) (GE Healthcare). Conditions for PCR were $95^{\circ} \mathrm{C} / 300 \mathrm{~s},\left(95^{\circ} \mathrm{C} / 30-40 \mathrm{~s}, 45-54^{\circ} \mathrm{C} / 30-45 \mathrm{~s}\right.$, $\left.72^{\circ} \mathrm{C} / 30-60 \mathrm{~s}\right) * 35$ cycles, $72^{\circ} \mathrm{C} / 480 \mathrm{~s}$. PCR products were purified using Exonuclease I (Fermentas) and FastAP Thermosensitive Alkaline Phosphatase (Fermentas) and sequenced at Macrogen Sequencing System, South Korea or at MWG Eurofins Operon in Edersberg, Germany. Genious 5.3 (Biomatters Ltd.) was used to obtain consensus sequences from assembled forward and reverse sequences, and to edit them. Alignments were made using Clustal X (Larkin et al. 2007) with default settings and then manually corrected in Geneious if necessary. Reading frame shifts were checked for the coding gene COI. Alignments resulted in $658 \mathrm{bp}$ of COI, $496 \mathrm{bp}$ of $16 \mathrm{~S}$ and $331 \mathrm{bp}$ of $28 \mathrm{~S}$ data. Trees were built using Bayesian inference (BA) and maximum likelihood (ML). For Bayesian analysis (BA) we used MrBayes v. 3.2.6 (Ronquist \& Huelsenbeck 2003). The best-fit models were selected using the Akaike information criterion (AIC) in MrModeltest v. 2.3 (Nylander 2004) in conjunction with PAUP* v. 4.0b10 (Swofford 2002). For COI, a partitioned site specific rate model was used: we applied the Symmetrical model of sequence evolution (SYM) with a proportion of the sites invariable for the COI $1^{\text {st }}$ codon position, the Felsenstein model (F81) for the COI $2^{\text {nd }}$ codon position and the Hasegawa-Kishino-Yano model (HKY) with gamma distributed rates across sites for the COI $3^{\text {rd }}$ codon position. For $16 \mathrm{~S}$, we applied the General Time Reversible model (GTR) with gamma distributed rates across sites. For 28S, the model selected was GTR with a proportion of the sites invariable. The number of generations was set to one million with four parallel chains (three hot and one cold), sample frequency to every $100^{\text {th }}$ generation, and number of runs to two. The first 2500 samples were discarded as the 'burn-in' of the Markov chain. We checked for stationary and convergence of the chains with TRACER v. 1.6 (Rambaut et al. 2014). For ML analysis we used the online version of RaxML BlackBox (Stamakis et al. 2008), with 100 bootstrap replicates by using the GTR $\Upsilon$ model. All model parameters were estimated by the program from its own maximum parsimony starting trees. The alignment was divided into the same 5 partitions as used for the Bayesian analysis. Phylogenetic relationships were considered strongly supported if posterior probabilities (pp) in Bayesian analysis were $\geq 0.95$ and/or bootstrap values (bv) in maximum likelihood analysis were $\geq 70 \%$ (Hillis \& Bull 1993; Alfaro et al. 2003). Uncorrected (p) sequence distances were generated using PAUP*.

Type specimens are deposited in the U.S. National Museum of Natural History, Smithsonian Institution, Washington, D.C., USA (USNM), California Academy of Sciences, Invertebrate Zoology, San Francisco, California, USA (CASIZ) and Museo Nacional de Ciencias Naturales, Madrid, Spain (MNCN). 


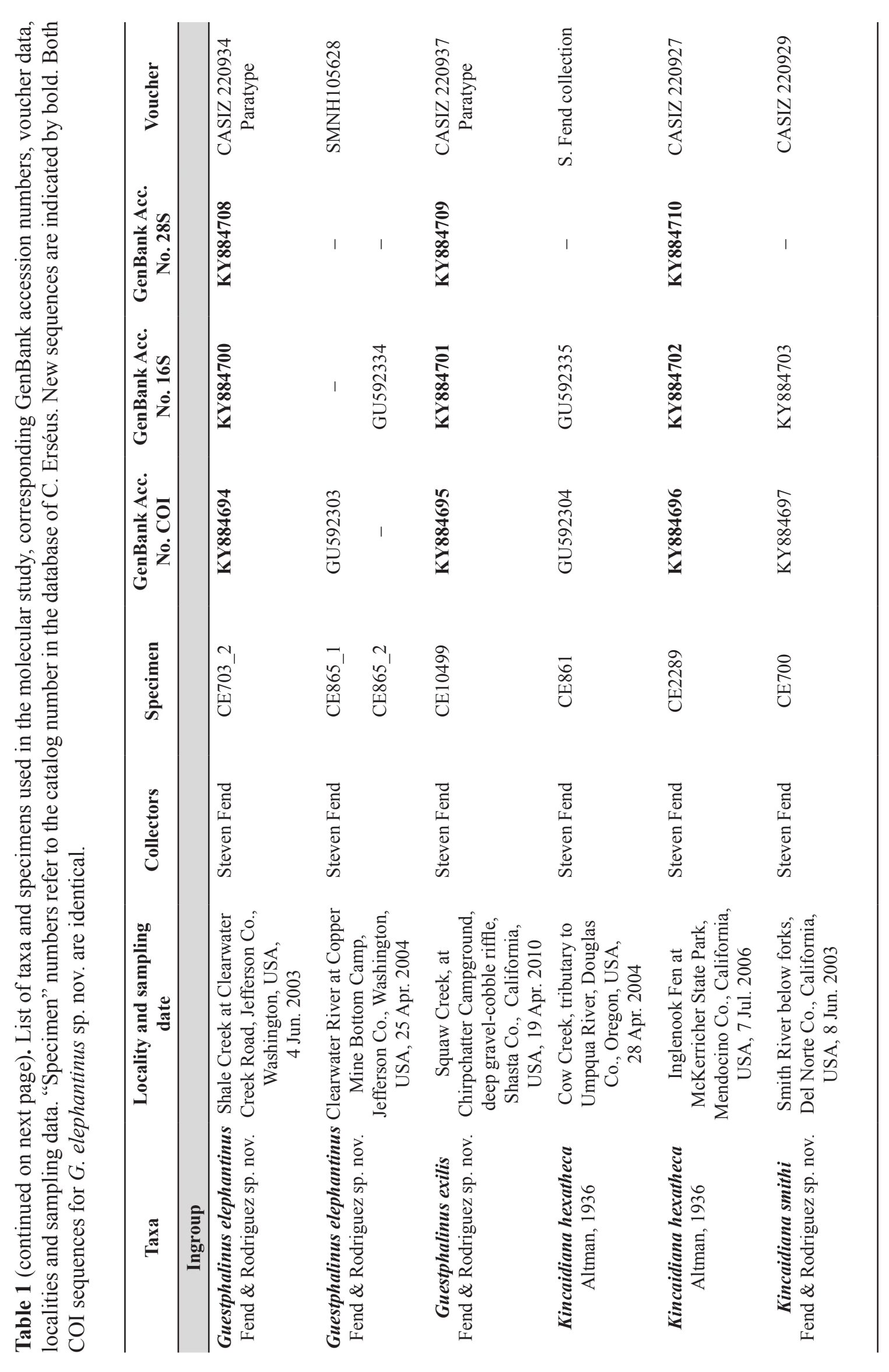




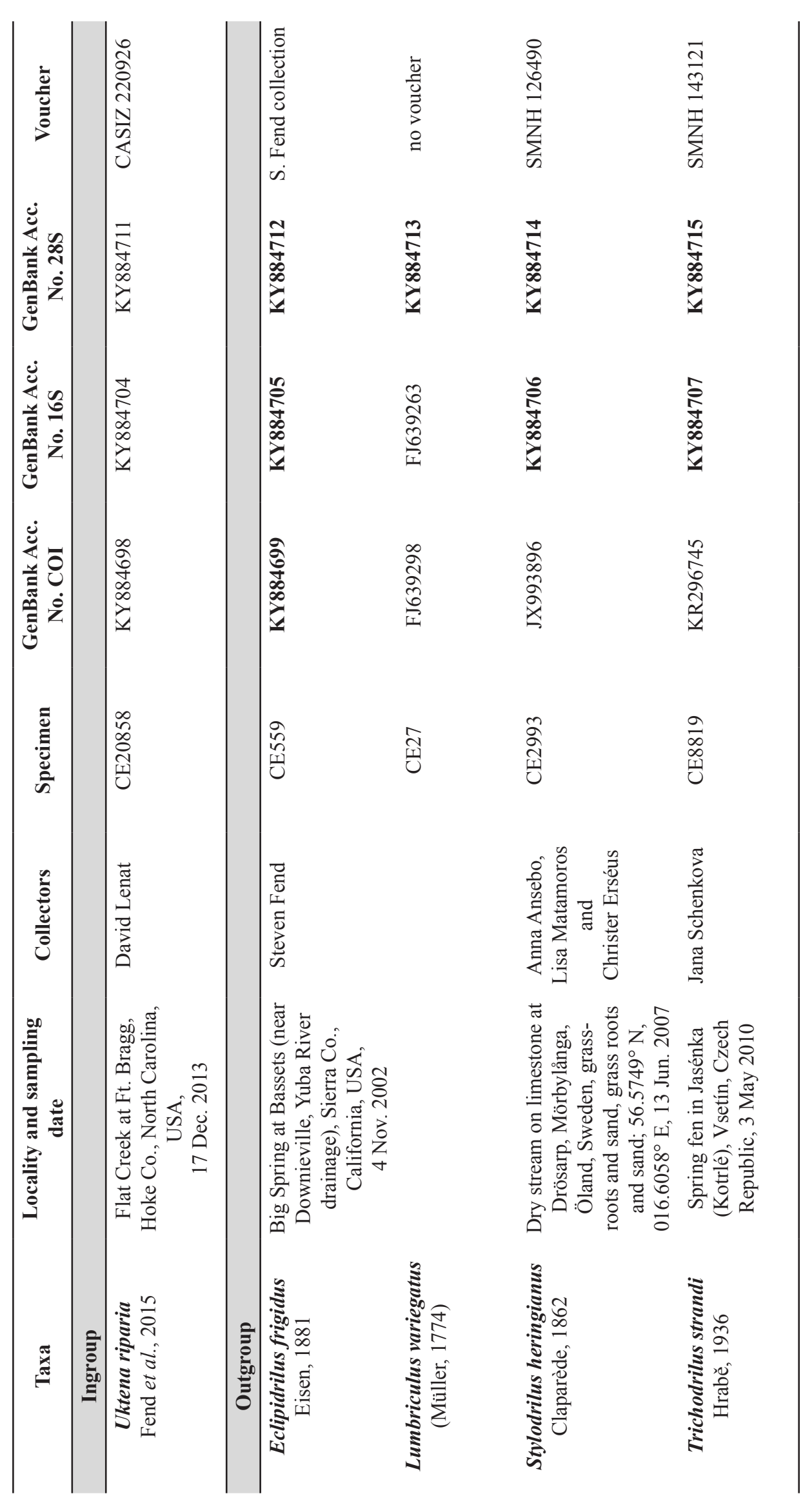


Generated sequences are deposited in GenBank. Additional material is retained in the collections of S. Fend, U.S. Geological Survey, Menlo Park, California, USA or P. Rodriguez, University of the Basque Country, Spain. Detailed information on specimens used for molecular analysis, with museum voucher and GenBank numbers, are given in Table 1. Additional site locality data, with geographic coordinates, are given in Appendix 1.

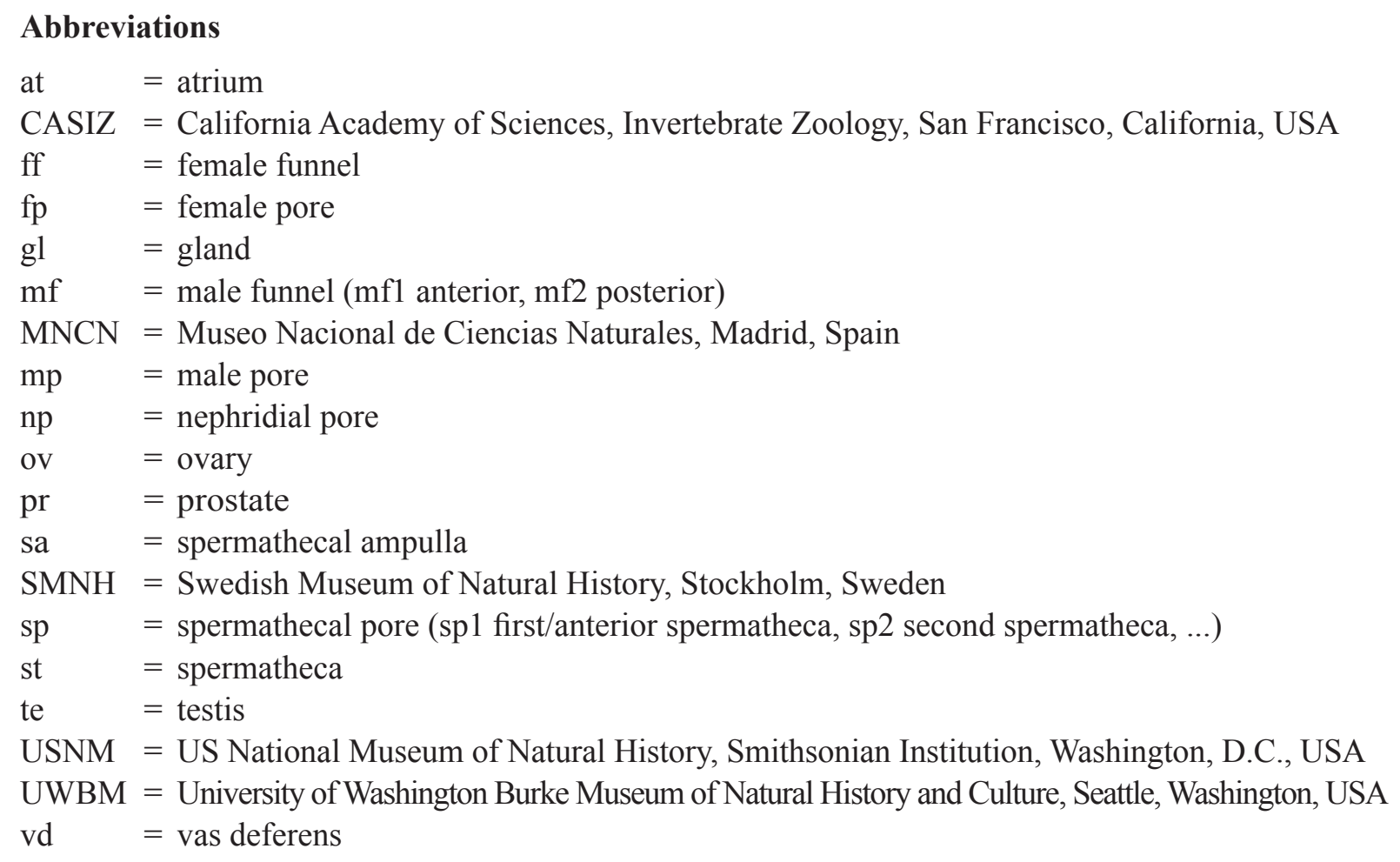

\section{Results}

Morphology

Class Clitellata Michaelsen, 1919

Order Lumbriculida Brinkhurst, 1971

Family Lumbriculidae Vejdovský, 1884

Kincaidiana Altman, 1936

\section{Type species}

Kincaidiana hexatheca Altman, 1936.

\section{Included species}

Kincaidiana hexatheca Altman, 1936

Kincaidiana smithi Fend \& Rodriguez sp. nov.

\section{Remarks}

The diagnosis in Fend (2009) is modified to include the new species with a single, median male pore and atrium, and spermathecal pores in line with ventral chaetae. New observations of several populations of $K$. hexatheca (see below) indicate that chaetae in anterior segments may appear as simple bifids (as 
in previous descriptions), but typically have more complex structure: a broad proximal tooth, a smaller dorsal tooth, and a thin dorsal keel. Anterior chaetae are rarely simple-pointed.

Altman (1936) described K. hexatheca and discussed the relationship of Kincaidiana to another proboscisbearing (Holarctic) genus, Rhynchelmis Hoffmeister, 1843, but made no mention of the European Guestphalinus wiardi (Michaelsen, 1933). Rhynchelmis differs from Kincaidiana, Guestphalinus and Uktena in having spermathecae only in segments anterior to the atria, and the (usually) semiprosoporous atria are (almost always) located in segment X. Kincaidiana freidris Cook, 1966 (later transferred to Altmanella Fend, 2009) has prosoporous atria in VIII; however, it differs from K. hexatheca in most other respects: it is a small worm, without a proboscis, and spermathecae are present only in the postatrial (not in the atrial) segment. The hexathecate condition, with three spermathecal segments beginning with the atrial segment, is only known in Kincaidiana and in Cookidrilus Rodriguez \& Giani, 1987. In the latter genus, there is no proboscis, the atria and spermathecae begin in X, instead of IX, and the male ducts are paired and semiprosoporous.

Kincaidiana hexatheca Altman, 1936

Figs 1-3

Kincaidiana hexatheca Altman, 1936: 64-68, figs 53-59, 66.

Kincaidiana hexatheca - Brinkhurst \& Cook 1966: 10, figs 2A, 5B, D, I. — Cook 1971: 237, figs 5.4 F-I, 5.5 D. - Fend 2009: 3-6, figs 1-2.

\section{Material examined}

\section{Lectotype}

UNITED STATES OF AMERICA: a sagittally sectioned worm on 4 slides, Series II, from the Altman collection, Washington, Pacific County, Loomis Lake, 11 Sep. 1929 (UWBM).

Other type material (Altman collection, UWBM)

UNITED STATES OF AMERICA: 1 dissected, same locality as lectotype, 14 Nov. 1931; 1 dissected, same locality as lectotype, 26 May 1932; 1 dissected, undetermined location (possibly Loomis Lake), 6 Apr. 1931; 1 dissected, undetermined location (possibly Loomis Lake), 23 Apr. 1931; 1 dissected, no date (\#199); additional syntypes were examined by Fend (2009, figs 2D-E, G-H).

New collections (mature specimens, unless otherwise noted)

UNITED STATES OF AMERICA: WASHINGTON: 2 sagittally sectioned, 2 dissected, several in alcohol, Jefferson County, small seep along Hoh River Road, 29 Apr. 1999, S. Fend leg.; 1 dissected, 2 in alcohol, same locality as preceding, 26 Apr. 2004, S. Fend leg.; 3 dissected, Hoh River drainage, roadside ditch, on Clearwater Road, 3 Jun. 2003, S. Fend leg.; 1 dissected, Pacific County, spring on Naselle River, 30 Apr. 1999, S. Fend leg.; 1 dissected, Clallam County, small pool along Bogachiel River on Undi Road, 26 Apr. 2004, S. Fend leg.; 1 mature, 3 post-mature, dissected, Clark County, Salmon Creek watershed, 10 Sep. 2001, R. Wisseman leg.; 2 partially-mature, dissected, Skamania County, Dog Creek near mouth, 26 Apr. 2014, P. Rodriguez and S. Fend leg. - OREGON: 2 dissected, 1 whole mount, Multnomah County, Oneonta Creek near mouth, downstream of Oneonta Gorge parking area, Columbia Gorge, 4 Jun. 2003, S. Fend leg.; 1 dissected (partially-mature), 1 whole mount, Tillamook County, small spring on Nestucca River 0.4 miles above Blaine, on Bible Creek Road, near Tillamook, 4 Jun. 2003, S. Fend leg.; 3 dissected, several in alcohol, Yamhill County, seep on east side of McGuire Reservoir near McMinnville, 4 Jun. 2003, S. Fend leg.; 7 dissected, several in alcohol, Lane County, muddy seep at Big Creek, FR5700, 11 May 2001, S. Fend leg.; 1 dissected, 1 in alcohol, same locality as preceding, 28 Apr. 2014, S. Fend leg.; 1 dissected, 4 immature, slide mounts, Lane County, 


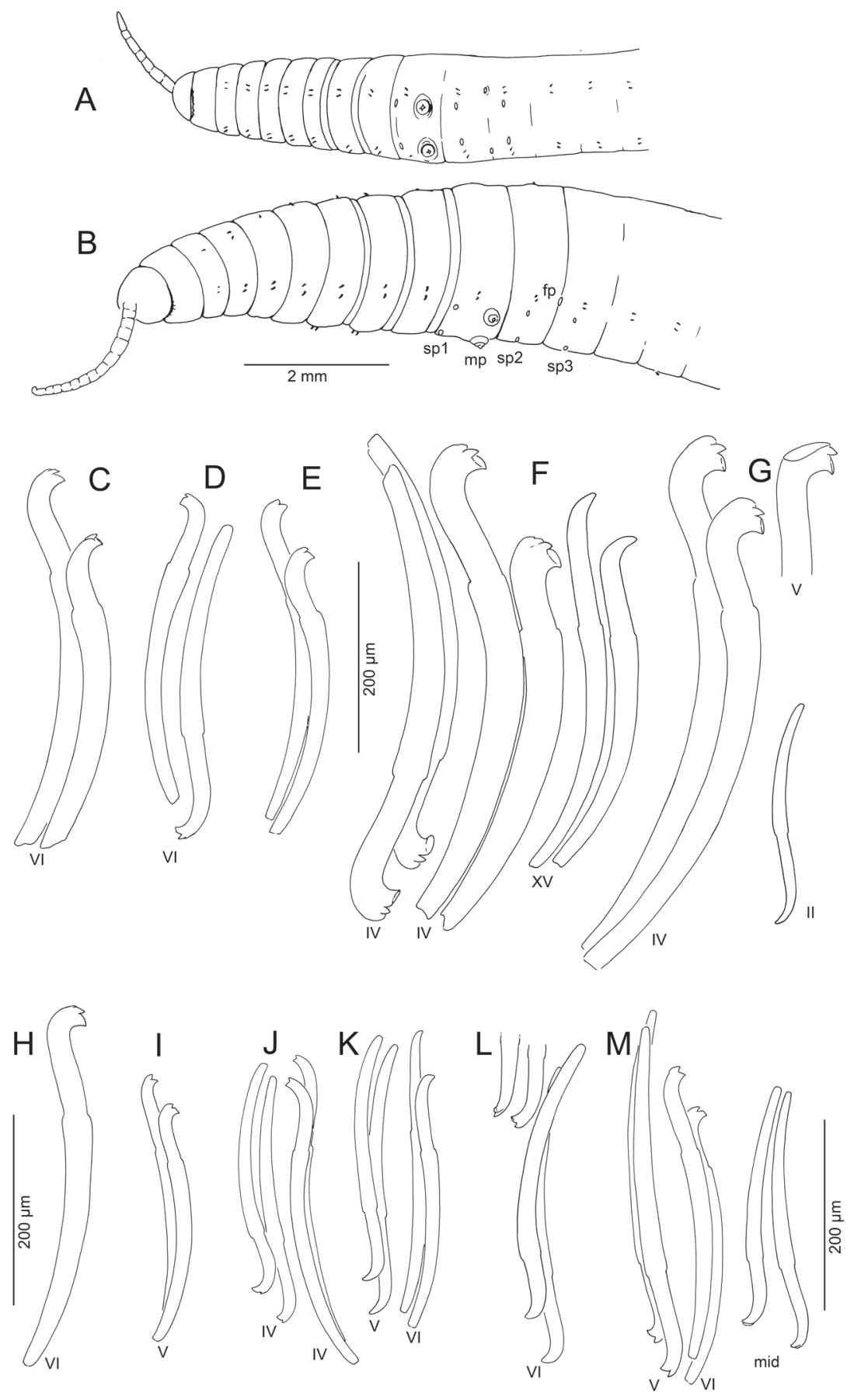

Fig. 1. Kincaidiana hexatheca Altman, 1936 from various sites. A-B. Complete worms, ventral view of anterior segments, from McKenzie River, OR (A), and from Big Creek, OR (B). C-M. Representative (mostly anterior) chaetae from different populations (ordered approximately north-south); dorsal chaetae with tips upward, ventrals with tips down. C. Hoh River, WA. D. Pool at Bogachiel River, WA. E. Salmon Creek watershed, WA, anterior dorsal pair. F-G. Two specimens from Big Creek, OR; tip of one dorsal chaeta with keel folded over. H. Rogue River, OR. I. From a Darlingtonia bog, O'Brien, OR. J-K. Two specimens from spring near Mule Creek, OR; K is from a smaller specimen, with simple-pointed chaetae. L. Illinois River, OR; older chaetae simple-pointed (worn?), replacements bifid. M. Inglenook Fen, CA. Scale bars: A-B $=2 \mathrm{~mm} ; \mathrm{C}-\mathrm{M}=200 \mu \mathrm{m}$. 

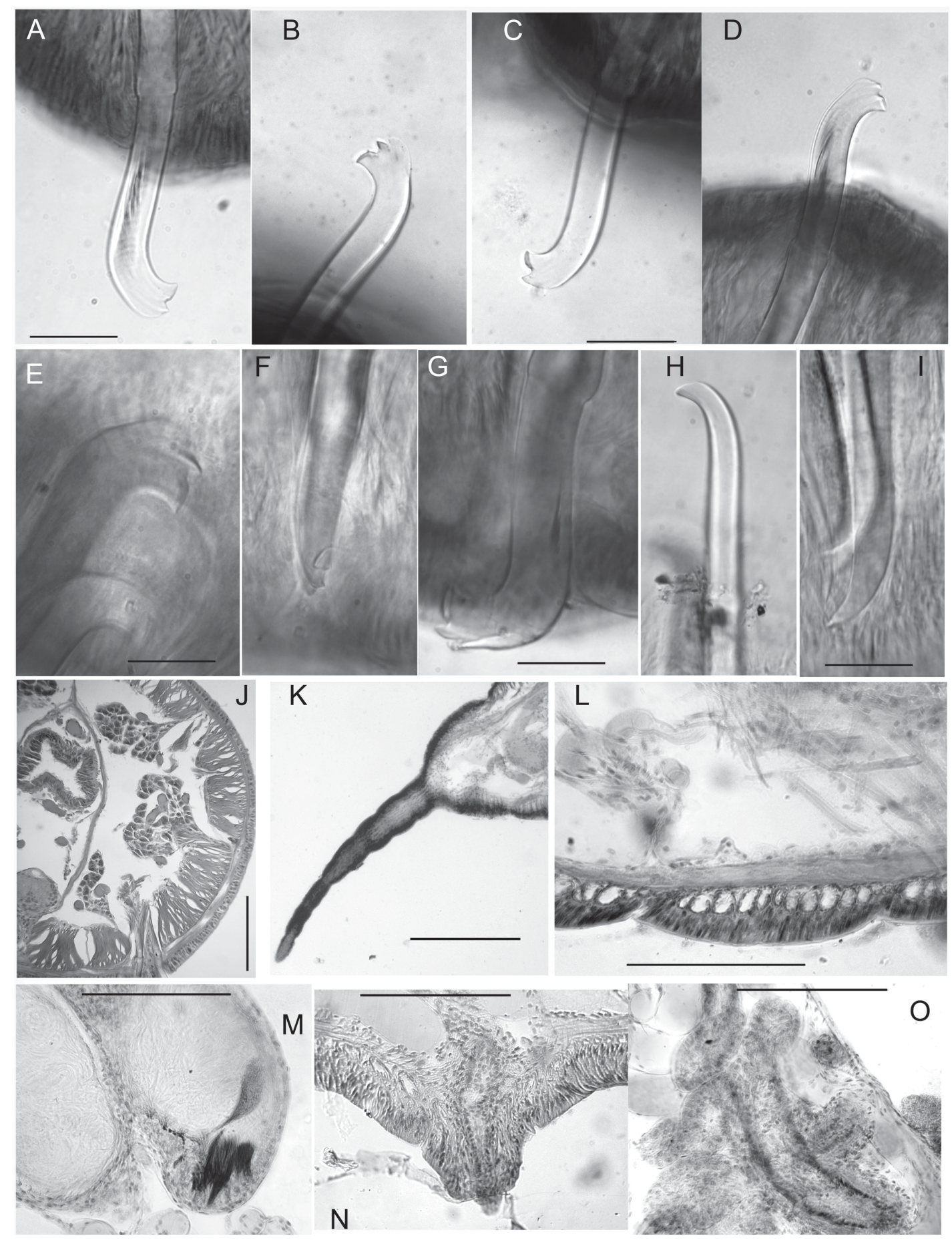

Fig. 2. Kincaidiana hexatheca Altman, 1936 from various sites. A, K-O from the sagittally sectioned lectotype, Loomis Lake, WA; B-C from Hoh River, WA; D from Inglenook Fen, CA; E-I from Big Creek, OR; J from O'Brien, OR. A-I. Tips of chaetae in anterior segments. A. IV ventral. B. VI dorsal. C. V ventral. D. V dorsal. E. IV dorsal. F. V ventral, frontal view. G. V ventral, chaeta with keel folded over. H. Dorsal, posterior segment. I. XV, ventral. J. Transverse section of anterior segment, showing 3-lobed pharyngeal gland. K. Ringed proboscis. L. Body wall in anterior segment, showing bands of circular muscle. M. Spermathecal ampulla, with concentrated sperm. N. Male porophore and penis. O. Atrium, prostate glands and vas deferens. Scale bars: $A-I=50 \mu \mathrm{m} ; \mathrm{J}, \mathrm{L}-\mathrm{O}=200 \mu \mathrm{m} ; \mathrm{K}=500 \mu \mathrm{m}$. 
small spring at mouth of Tenmile Creek, 1 May 1999, S. Fend leg.; 1 whole mount (immature), Lane County, marsh at base of Mt Pisgah, near Eugene, 29 Jan. 2000, S. Fend leg.; 6 dissected, Lane County, outflow from Leaburg fish hatchery (McKenzie River), 19 May 2013, S. Fend leg.; 1 dissected, 2 in alcohol, Whittaker Creek at Siuslaw River, 12 Aug. 2016, S. Fend leg.; 3 immature whole mounts (1 is DNA voucher CE861), Douglas County, Cow Creek, tributary to Umpqua River, 28 Apr. 2004, S. Fend leg.; 6 dissected, 2 in alcohol, Douglas County, spring above Mule Creek, 7 Jun. 2003, S. Fend leg.; 1 transverse section, 4 dissected, 5 whole mounts, Josephine County, Darlingtonia bog near O'Brien, off Wimer-Lone Mt Road, 26 Oct. 1999, S. Fend leg.; 1 whole mount, Josephine County, Illinois River near Sixmile Creek, 25 Oct. 1999, S. Fend leg.; 1 whole mount, same locality as preceding, 7 Jun. 2003, S. Fend leg.; 1 dissected, 1 whole mount, same locality as preceding, 21 May 13, S. Fend leg.; 3 dissected, 1 whole mount, 3 immature dissected, Curry County, Rogue River at Quosatana Campground (NFS) ca 19 miles above Gold Beach, 8 Jun. 2003, S. Fend leg. - CALIFORNIA: 9 dissected (plus 3 immature dissected), Mendocino County, Inglenook Fen at McKerricher State Park, slow creek, roots of Apiaceae, 1 Jul. 2005, S. Fend leg.; 1 dissected DNA voucher, same locality as preceding, 7 Jul. 2006, S. Fend leg. (CE2289).

\section{Molecular data}

COI, 16S, and 28S sequences are from two specimens, collected at Inglenook Fen, California and Cow Creek, Oregon (details in Table 1).

\section{Description of new material}

Size variable (Table 2); specimens from swampy habitats usually larger than those from gravel-bed streams; largest specimens (length $>100 \mathrm{~mm}$, diameter $>2 \mathrm{~mm}$, segments $>200$, Fig. 1B) from muddy seeps in Oregon. No obvious latitudinal difference in size (see length, width and segment numbers in Table 2). Largest specimens considerably larger than material collected by Altman (1936) (diameter $0.75-1.25 \mathrm{~mm}$ ) from two sites in Washington and one in Oregon. Proboscis elongate, appearing ringed externally, but lacking internal septa (Figs 1A-B, 2K).

Chaetae in anterior segments (II to VI, VII or VIII) almost always modified, with distal ends oriented anteriad. Modified anterior chaetae may appear simply bifid in lateral view, with short upper tooth (Figs 1C, 2C), but structure usually more complex: lower tooth broad and flattened or concave, and thin dorsal keel may extend beyond upper tooth (Figs $1 \mathrm{~F}-\mathrm{G}, 2 \mathrm{~A}-\mathrm{B}, \mathrm{E}-\mathrm{G})$. Keel visible as translucent outer edge in lateral view, or narrow point in frontal view (Fig. 2F); usually most prominent on replacement chaetae, but absent on many chaetae, possibly due to wear; keel often broken or folded over (Figs 1G, $2 \mathrm{G}$ ) in mounted specimens, with chaeta appearing trifid. This structure occurs throughout the geographic range of the species, but not always visible in specimens from some populations. Chaetae in atrial and postatrial segments usually simple-pointed, moderately sigmoid and oriented posteriad; tips slightly keeled in posterior segments on some specimens (Fig. 1M).

Chaetae in segment II always smaller than those in next several segments; ventrals in II usually simplepointed. Chaetae from III to about VII or VIII usually thicker than (but similar in length, see Table 2) to those in following segments, with more distal nodulus; distinctly longer in some individuals, and up to $50 \%$ longer in Big Creek (west-central Oregon) worms. Within a bundle, inner chaeta typically longer than outer, with more proximal nodulus (Fig. 1C, F). Greatest modification in size, position of nodulus, and development of teeth in anterior chaetae in specimens from Big Creek (Figs 1F-G, 2E-G).

Pharynx with high columnar cells from II to IV, with dorsal and lateral epithelium higher than ventral. Intestine begins in 6/7. Pharyngeal glands in V or VI to VII or VIII, on each side produced into 3 irregular, anteriorly directed lobes (Fig. 2J) joining at the base (posterior septum). Contrary to the description by Altman (1936), they were never observed in II or III, and are about equally distributed dorsally 
Table 2. Descriptive measurements (mean, range, and n) for Kincaidiana hexatheca Altman, 1936 from different regions (from north to south: Washington, Oregon and California), and K. smithi Fend \& Rodriguez sp. nov.

\begin{tabular}{|c|c|c|c|c|c|c|c|c|c|c|c|c|}
\hline & 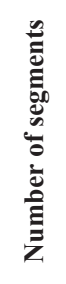 & 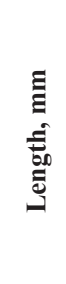 & 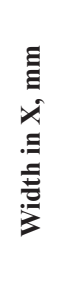 & 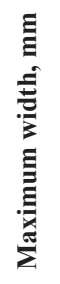 & 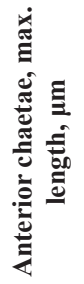 & 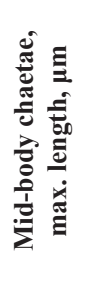 & 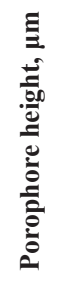 & 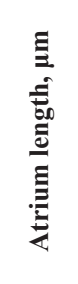 & 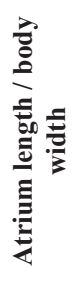 & 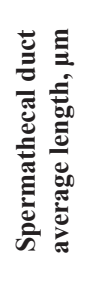 & 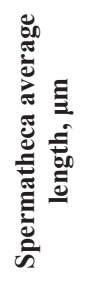 & 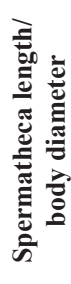 \\
\hline \multicolumn{13}{|c|}{ K. hexatheca Altman, 1936: Washington, USA } \\
\hline mean & 176 & 73 & 1.6 & 1.8 & 401 & 369 & 135 & 941 & 0.53 & 451 & 1563 & 0.83 \\
\hline $\max$ & 220 & 95 & 2.1 & 2.2 & 446 & 396 & 170 & 1230 & 0.64 & 563 & 1913 & 0.92 \\
\hline $\min$ & 146 & 62 & 1.1 & 1.2 & 335 & 314 & 80 & 690 & 0.47 & 246 & 1156 & 0.79 \\
\hline $\mathrm{n}$ & 11 & 11 & 19 & 18 & 8 & 8 & 10 & 11 & 8 & 11 & 5 & 4 \\
\hline \multicolumn{13}{|c|}{ K. hexatheca Altman, 1936: Oregon, USA } \\
\hline mean & 172 & 75 & 1.5 & 1.7 & 347 & 322 & 90 & 806 & 0.57 & 411 & 1292 & 0.91 \\
\hline $\max$ & 289 & 183 & 2.6 & 2.8 & 628 & 555 & 140 & 1230 & 0.96 & 598 & 1770 & 1.18 \\
\hline $\min$ & 92 & 40 & 0.7 & 1.0 & 199 & 214 & 60 & 209 & 0.24 & 120 & 545 & 0.70 \\
\hline $\mathrm{n}$ & 40 & 44 & 58 & 58 & 30 & 30 & 7 & 21 & 19 & 22 & 16 & 14 \\
\hline \multicolumn{13}{|c|}{ K. hexatheca Altman, 1936: California, USA } \\
\hline mean & 183 & 70 & 1.3 & 1.4 & 320 & 300 & 93 & 922 & 0.72 & 442 & 1498 & 1.15 \\
\hline $\max$ & 235 & 104 & 1.9 & 2.1 & 385 & 372 & 160 & 1300 & 0.91 & 520 & 2165 & 1.42 \\
\hline $\min$ & 130 & 48 & 1.1 & 1.2 & 259 & 244 & 44 & 725 & 0.59 & 355 & 985 & 0.90 \\
\hline $\mathrm{n}$ & 7 & 9 & 12 & 10 & 14 & 14 & 8 & 11 & 9 & 11 & 10 & 6 \\
\hline \multicolumn{13}{|c|}{ K. smithi Fend \& Rodriguez sp. nov.: Smith River, California, USA } \\
\hline mean & 144 & 55 & 1.2 & 1.3 & 353 & 302 & 167 & 1169 & 1.02 & 472 & 1318 & 1.04 \\
\hline $\max$ & 165 & 68 & 1.5 & 1.8 & 472 & 369 & 202 & 1620 & 1.18 & 717 & 1915 & 1.32 \\
\hline $\min$ & 117 & 42 & 1.0 & 1.1 & 274 & 245 & 100 & 825 & 0.75 & 264 & 857 & 0.76 \\
\hline $\mathrm{n}$ & 9 & 9 & 13 & 13 & 10 & 10 & 6 & 9 & 8 & 12 & 13 & 7 \\
\hline
\end{tabular}

and ventrally. Nephridia begin on 11/12, with narrow, dorsally-directed postseptale, as described by Fend (2009). Circular muscle layer of body wall forms distinct bands in anterior segments (Fig. 2L).

Lateral trunks of dorsal blood vessel join to form ventral vessel in III or IV, anterior to location in Altman's description (V). Unbranched, but highly convoluted commissural vessels in anterior segments to about XX. One or two pairs of lateral vessels in segments posterior to about XX; morphology of these vessels variable in middle segments; most commonly, the anterior is larger, branched and covered in chloragogen cells; alternatively, the posterior pair may be branched, and the anterior pair simple, as stated by Altman (1936). Posterior segments may have two pairs of branched vessels.

Male pores always paired, median and posterior to ventral chaetae on IX (Fig. 1A-B); conical porophores developed (Fig. 2N) or not (Fig. 3B-C). Spermathecae paired in IX, X, and XI; spermathecal pores slightly displaced towards ventral midline; pores in IX slightly anterior to chaetae, those in X-XI level with chaetae (Fig. 1A-B). 
Atria generally more elongate-tubular than in the illustration by Altman (1936: fig. 59) (Fig. 3). Atrial ampulla and ectal duct weakly differentiated, ampulla distinguished only by slightly greater diameter and presence of prostates (Fig. 2O). Atrium length, including length relative to body width, shows overlap among regions (Table 2). Atria usually entirely in IX, but extend into $\mathrm{X}$ in four specimens from sites throughout the species distribution (Fig. 3C). Male funnels may be displaced back within sperm sacs as far as XI (Fig. 3A, C) or even XII.

Spermathecal duct about 300-600 $\mu \mathrm{m}$ long, tubular, histologically differentiated from ampulla, having thick, irregular epithelium of columnar cells and more well-developed muscular layer. Duct may be sharply constricted at ectal end, as it joins a narrow epidermal infolding. Spermathecal ampulla 800$1600 \mu \mathrm{m}$ long; sharply expanded in basal part in some specimens (Fig. 3B), as in the original description (Altman 1936: fig. 57), but more typically elongate-tubular (Fig. 3A, C-D). Sperm usually lined up along epithelium near ectal end of ampulla (Figs 2M, 3D), absent in the duct.

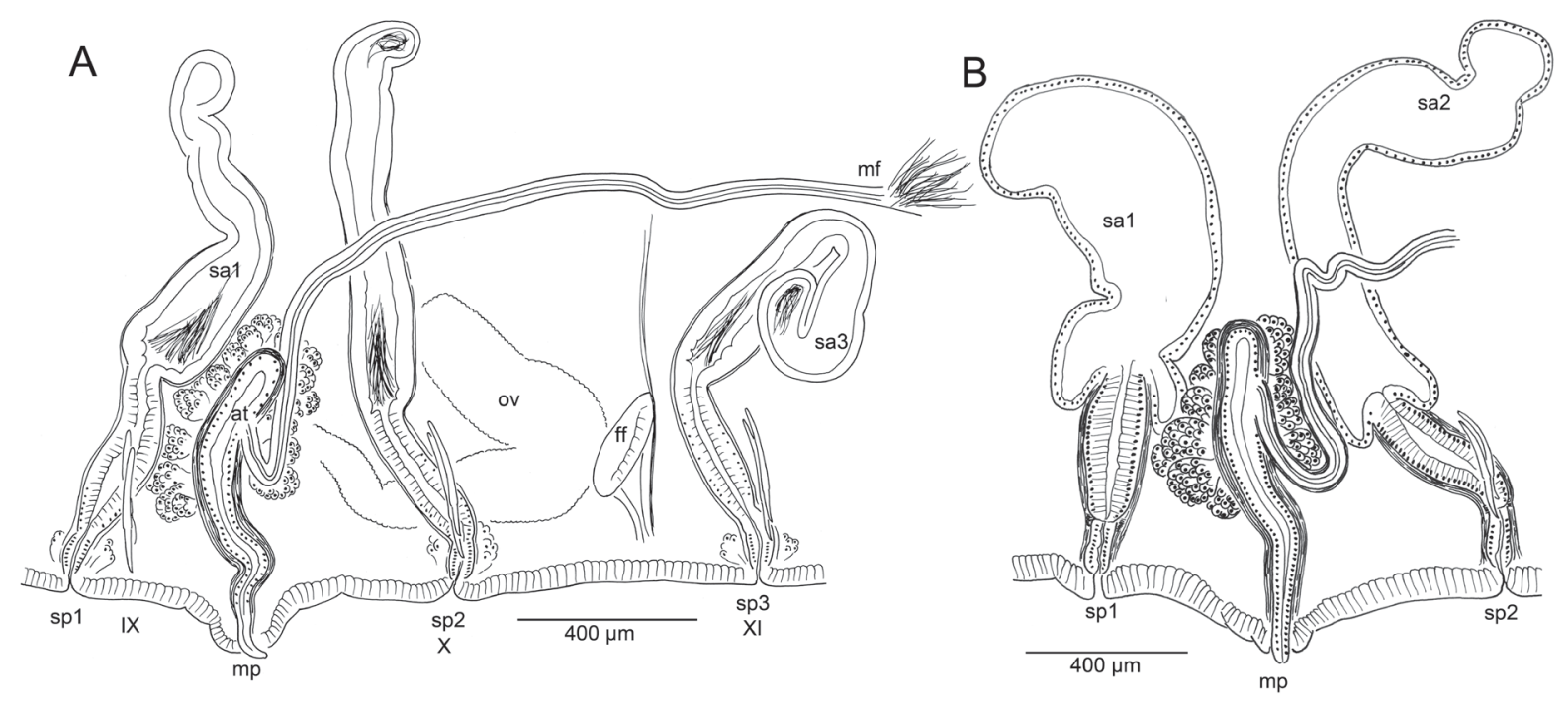

$\mathrm{C}$
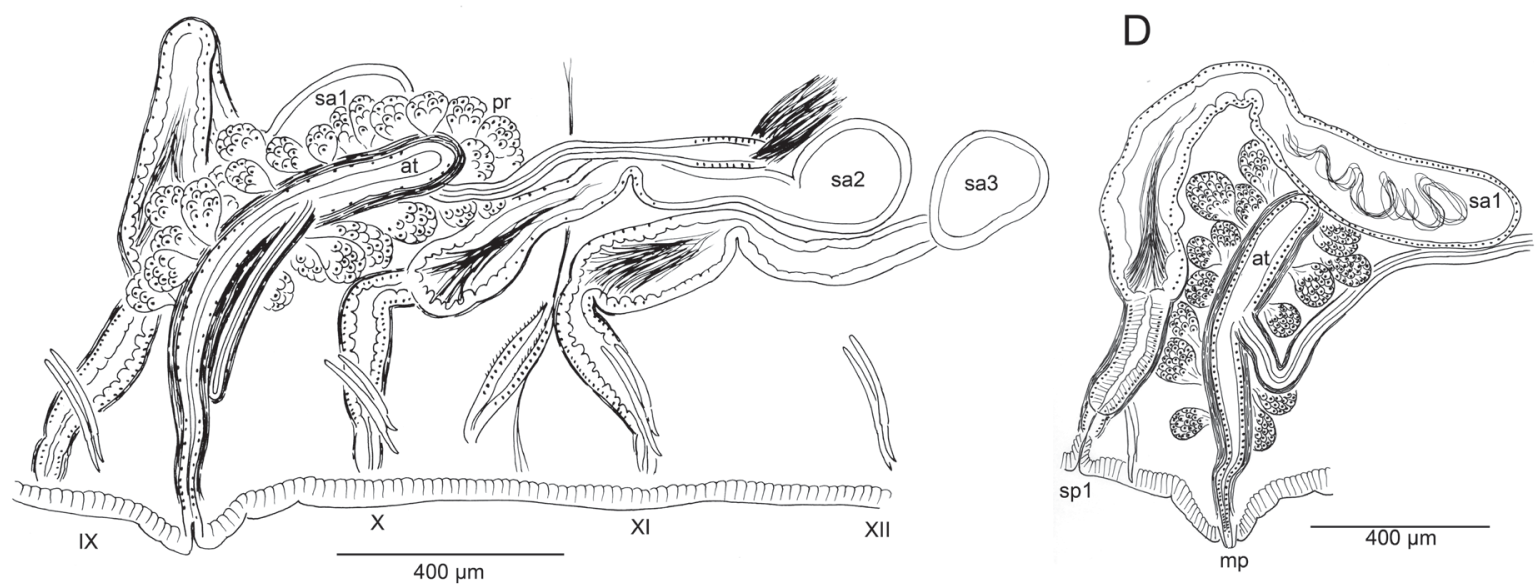

Fig. 3. Kincaidiana hexatheca Altman, 1936, reproductive organs. A-B. From Hoh River, WA; (A) segments IX-XI; (B) atrium and spermathecae with expanded ampullae in IX-X. C-D. From Rogue River, OR; (C) reproductive organs in IX-XI from an atypical worm with long atria; (D) atrium and spermatheca in IX, from a typical worm. 


\section{Remarks}

The type series was not clearly designated by Altman (1936), and material used in the original description appears to have been collected from 3 sites in southwestern Washington and northwestern Oregon. The sagittally sectioned specimen here designated as the lectotype (Fig. 2A, K-O) shows most of the diagnostic characters: annulated proboscis, bifid/keeled anterior chaetae, spermathecae paired in atrial and 2 postatrial segments, conical male porophores, short-tubular atria with prosopore male ducts paired in IX. Other worms from the type series (mostly from undetermined localities) also show these characters (see fig. 2D-E, G in Fend 2009).

In addition to examining 18 apparent syntypes, Fend (2009) verified diagnostic characters in specimens from additional sites in Washington, Oregon, and California, but did not discuss regional or population differences. Here we examine variation in morphological characters in specimens from throughout the known geographic distribution of the species and molecular differences between specimens from two sites in the southern part of the range, near the type locality of Kincaidiana smithi sp. nov. (see below).

The bifid, anteriorly-directed chaetae in preclitellar segments are one of the most distinctive characters for $K$. hexatheca. Despite some population differences in size of these chaetae, the general pattern was consistent in most populations. However, the occurrence of worms from a few sites in southwestern Oregon, having typical $K$. hexatheca reproductive organs, but with simple-pointed or only slightly bifid anterior chaetae, cautions against reliance on this character alone for identifying immature specimens. All chaetae (including replacements) were simple-pointed in a partially-mature specimen from Cow Creek (Umpqua River drainage), and immature worms from the same site were similar; chaetae in the first few anterior segments were not enlarged, although they were anteriorly-directed. This condition was variable in mature and immature specimens from two sites in the Rogue River drainage: a spring near Mule Creek (Fig. 1J-K) and the Illinois River (Fig. 1L); in one such specimen the replacement chaetae are bifid (Fig. 1L), but in other individuals all chaetae (including replacements) were simplepointed. This suggests that simple-pointed chaetae do not simply reflect wear in worms from gravel-bed streams.

There was no obvious latitudinal difference in size and exent of modification of anterior chaetae (Table 2). The maximum chaeta length in anterior segments of several populations was considerably larger than the $0.218 \mathrm{~mm}$ reported by Altman (1936).

Morphology of reproductive organs varied within populations (Fig. 3), possibly masking regional differences. Our observations differ from prior descriptions in minor details. Cook (1971) stated that spermathecal pores are behind the ventral chaetae in IX, but Altman (1936) placed them "between, and just ventral" (median?) to the ventral chaetae. All of the new material has spermathecal pores distinctly displaced towards the ventral midline, and the first pair is clearly anterior to the ventral chaetae (Fig. 1A-B). Atrium length varied by about a factor of 2 within each region, although this was less when normalized by body diameter (Table 2). The limited data suggest that atria of specimens in the California population were larger relative to body size. Spermatheca size varied similarly due to the elongate, irregular ampullae; however, the duct length was less variable.

The species appears to be endemic to the Pacific northwestern USA and British Columbia (Kathman \& Brinkhurst 1998); reported records from other regions cannot be verified, as material was mostly unavailable for study. Some confusion may be based on ambiguous somatic characters regarded as distinctive in published keys (e.g., Kathman \& Brinkhurst 1998). In particular, wrinkling due to fixation of other proboscis-bearing species may be interpreted as a "pseudo-segmented" proboscis, and minutely bifid chaetae (possibly a result of wear) on some specimens of Rhynchelmis may also cause confusion. For example, Spencer \& Denton (2003) tentatively attributed immature specimens from 
Utah to $K$. hexatheca, but recent examination by one of the authors (S. Fend) of some of this material deposited in the Bean Life Science Museum (Brigham Young University, Provo, Utah) suggested that they were more likely to be a species of Rhynchelmis. Therefore, morphology-based identification of immature specimens of $K$. hexatheca should ideally be based not only on the proboscis and presence/ absence of modified anterior chaetae, but also on other morphological characters. For example, two pairs of lateral blood vessels in segments X-XX of the Nearctic Rhynchelmis species (if present) are short, usually branched, and do not join the ventral vessel (Fend \& Brinkhurst 2000).

\section{Habitat}

Kincaidiana hexatheca has been collected in many coldwater habitats, ranging from cobble riffles in large streams to small, muddy seeps, typically associated with aquatic plants (e.g., skunk cabbage, Lysichiton americanus Hultén \& St. John and water parsley, Oenanthe sarmentosa Presl).

Kincaidiana smithi Fend \& Rodriguez sp. nov. urn:1sid:zoobank.org:act:9485884B-2496-42B0-8488-5A1A89514F9C

Figs 4-5

\section{Etymology}

Named for Prof. Jerry Smith, in recognition of his contributions to the ecology and management of Pacific coastal streams.

\section{Material examined}

Holotype

UNITED STATES OF AMERICA: a dissected worm, stained in hematoxylin and mounted in Canada balsam, California, Del Norte County, Smith River below forks, 8 Jun. 2003, S. Fend leg. (USNM 1422281).

\section{Paratypes}

UNITED STATES OF AMERICA: 1 dissected, same data as for holotype (USNM 1422282); 1 dissected, same data as for holotype (CASIZ 220930); 1 sagittally sectioned, same locality as for holotype, 10 May 2009, S. Fend and P. Rodriguez leg. (CASIZ 220928); 1 dissected, seep by South Fork Smith River, 10 May 2009, S. Fend and P. Rodriguez leg. (CASIZ 220931); 1 dissected, same data as preceding (MNCN $16.03 / 3102)$.

Additional material (all partially-mature)

UNITED STATES OF AMERICA: 1 sagittally sectioned, 2 dissected, 1 whole mount, 3 in alcohol, from type locality, 8 June 2003; 2 dissected, same locality as preceding, 10 May 2009.

\section{Molecular data}

COI and 16S sequences correspond to topotypic voucher CASIZ 220929 (details in Table 1).

\section{Description}

Medium-sized to large worms (Table 2); prostomium short, length about $1 / 2$ width; filiform proboscis 1-2 $\mathrm{mm}$ long, $0.1-0.16 \mathrm{~mm}$ diameter, not widened at base, externally ringed with multiple shallow constrictions (Fig. 4A). Body segmentation externally distinct in anterior segments, weak in clitellum and posteriorly; secondary annulation may appear as a narrow posterior ring in V-VII or VIII.

Chaetae two per bundle; those in II to (VII)VIII (IX) directed anteriad, others directed posteriad. Chaetae in II or III to VI or VIII appear bifid with large, flat ventral tooth and thinner dorsal tooth (Fig. 5D-E); 


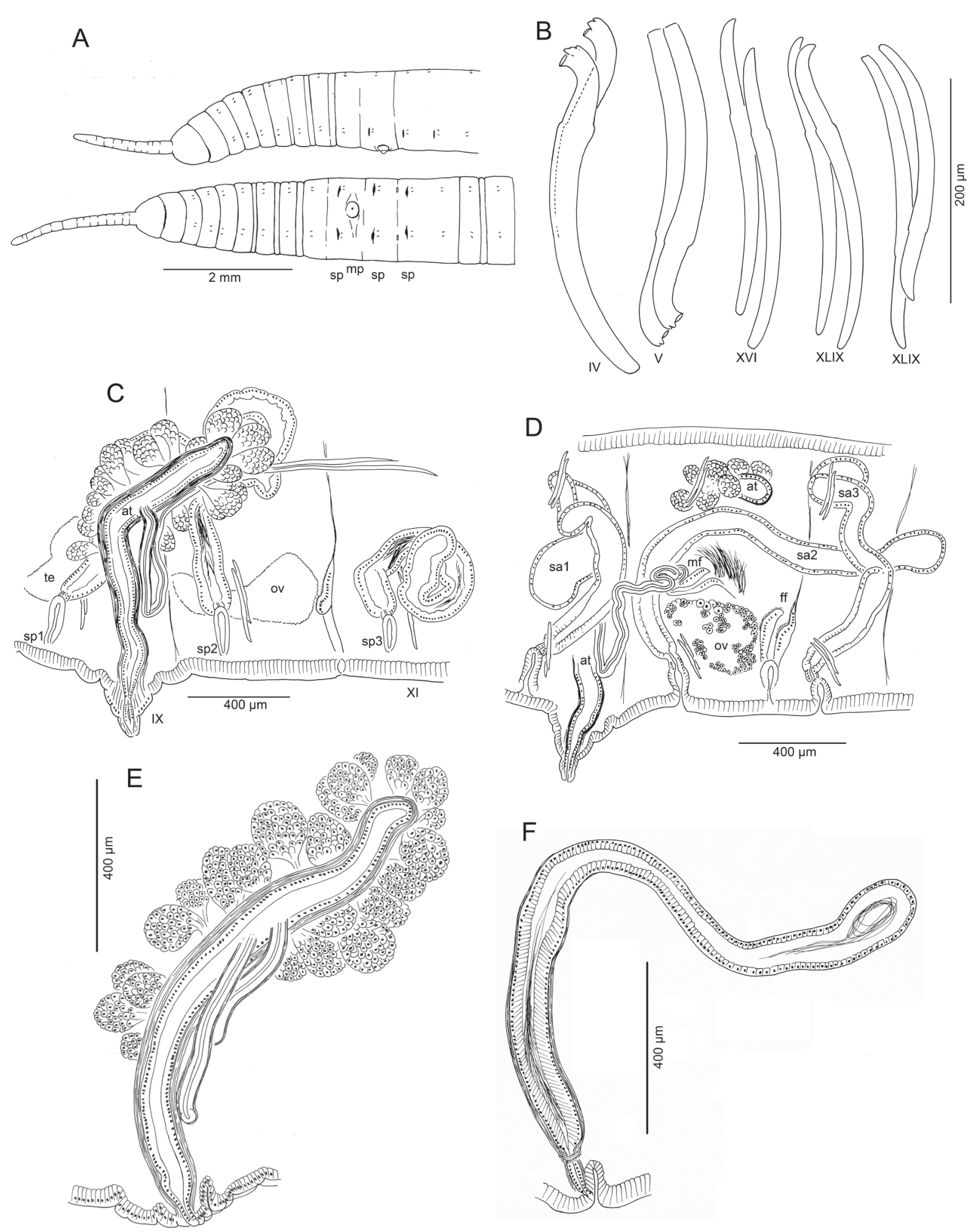

Fig. 4. Kincaidiana smithi Fend \& Rodriguez sp. nov., from the type locality, except for C, from seep by South Fork Smith River, CA. A. Complete worm, lateral and ventral views, showing location of reproductive pores. B. Representative chaetae: Roman numerals indicate segment number; dorsal chaetae with tips upward, ventrals with tips down. C. Reproductive organs in IX-XI. D. Reproductive organs in IX-XI, from a sagittal section (middle portion of atrium missing). E. An atrium, joined by both vasa deferentia. F. A spermatheca. 
some chaetae with a thin dorsal keel above the upper tooth (Fig. 4B). Modified anterior chaetae strongly arcuate distal to the nodulus; shortest in II, gradually increasing in size from III to VI, maximum anterior chaeta length $270-470 \mu \mathrm{m}$. Within each pair, median (inner) chaeta has nodulus $0.3-0.4$ the distance from the tip; lateral (outer) chaeta may be slightly thicker, with more distal nodulus, $0.25-0.3$ distance from tip. Chaetae in IV-VII may be longer and thicker (width 15-22 $\mu \mathrm{m}$ ) than more posterior chaetae (width 11-15 $\mu \mathrm{m}$ ). Posterior to VI-VIII, chaetae usually simple-pointed (Fig. 4B), moderately sigmoid, and directed posteriad; dorsals about the same length as ventrals. Within each posterior pair, lateral chaeta has slightly more distal nodulus. Chaetae in segments posterior to about LXXX may be strongly arcuate; dorsal pairs may appear slightly bifid or with an upper keel (Fig. 5F).

Epidermis in anterior segments $25-32 \mu \mathrm{m}$ thick; in clitellum 50-70 $\mu \mathrm{m}$, thinner in posterior segments. Clitellum from about mid-VII to mid-XIII. In anterior segments, circular muscle layer of body wall arranged in a series of transverse bands with gaps between (Fig. 5B); this layer is $25-50 \mu \mathrm{m}$ thick in pre-clitellar segments, gradually narrowing posteriorly down to 5-7 $\mu \mathrm{m}$ and appearing homogeneous. Longitudinal muscle layer of body wall $70-100 \mu \mathrm{m}$ thick in anterior and middle segments. Pharynx from I-III or IV, with dorsal and lateral wall moderately thickened; transition to esophagus indistinct. Pharyngeal glands V-VII, with dorsolateral, median and ventrolateral lobes joining at posterior septa; lobes are joined between segments by thin extensions. No abrupt division between esophagus and intestine. Chloragogen cells cover gut beginning in VII. Brain in the peristomium, not deeply lobed.

Dorsal blood vessel separate from gut to about VIII, then closely appressed posteriorly. One pair of commissural blood vessels join dorsal blood vessel near posterior septum between II and about $\mathrm{XX}$; these vessels lack a dense chloragogen layer; in pre-clitellar segments they are long and sinuous; those originating in II-VI join the ventral vessel(s) in the next segment; posteriorly, they are shorter, and join both dorsal and ventral vessels in the same segment. A pair of lateral, blind blood vessels, covered with chloragogen cells, joins the dorsal vessel in the anterior part of segments beginning in about XVI; at first, these are short and unbranched, but by XXV they reach the ventral part of the body, and have up to 10 long branches; by XL they may have more than 20 branches and fill much of the coelom. A second pair of blind, branched lateral blood vessels is located in the posterior part of each segment, posterior to about segment $\mathrm{L}$. In more posterior segments (by about $\mathrm{C}$ ), both pairs of lateral vessels have many short dorsal branches.

Nephridia usually paired on 11/12; occurring irregularly in posterior segments, absent from many segments. A small anteseptal funnel is followed by narrow, dorsally-directed, granular postseptal mass (Fig. 5C). Efferent duct forms a closely-appressed loop, extending to dorsal part of body cavity, forming a convoluted mass; duct ends in a narrow vesicle in front of ventral chaetae in the originating segment; nephridiopore inconspicuous.

Male pore single, median and posterior to ventral chaetae on IX; ectal tip of the atrial duct protrudes as a short penis. When everted, penis is subtended by a conical, tiered porophore (Fig. 5M-N), the entire structure up to about $200 \mu \mathrm{m}$ high by $250-300 \mu \mathrm{m}$ wide at base; porophore circular, usually consisting of two concentric epidermal folds. Spermathecae paired in IX, X, and XI; spermathecal pores on or very slightly median to ventral chaetal lines, all slightly anterior to respective chaetae (Figs 4A, 5A). One pair of testes in IX, reaching to mid-segment; one pair of ovaries in X, extending to back of segment or into XI; female funnels intersegmental in 10/11, up to $280 \mu \mathrm{m}$ high. Sperm sacs extend posteriad to XVII-XXIV; no anterior sperm sacs; egg sacs with large eggs extend 1-2 segments behind sperm sacs.

Spermathecal ducts terminate within narrow vestibules, $100-130 \mu \mathrm{m}$ deep; junction usually constricted by a muscular ring, forming a short sphincter (Fig. 5K). Spermathecae nearly tubular, about 1000$2000 \mu \mathrm{m}$ long, weakly divided into two sections, both of which may contain sperm (Figs 4F, 5H-J). Ectal 

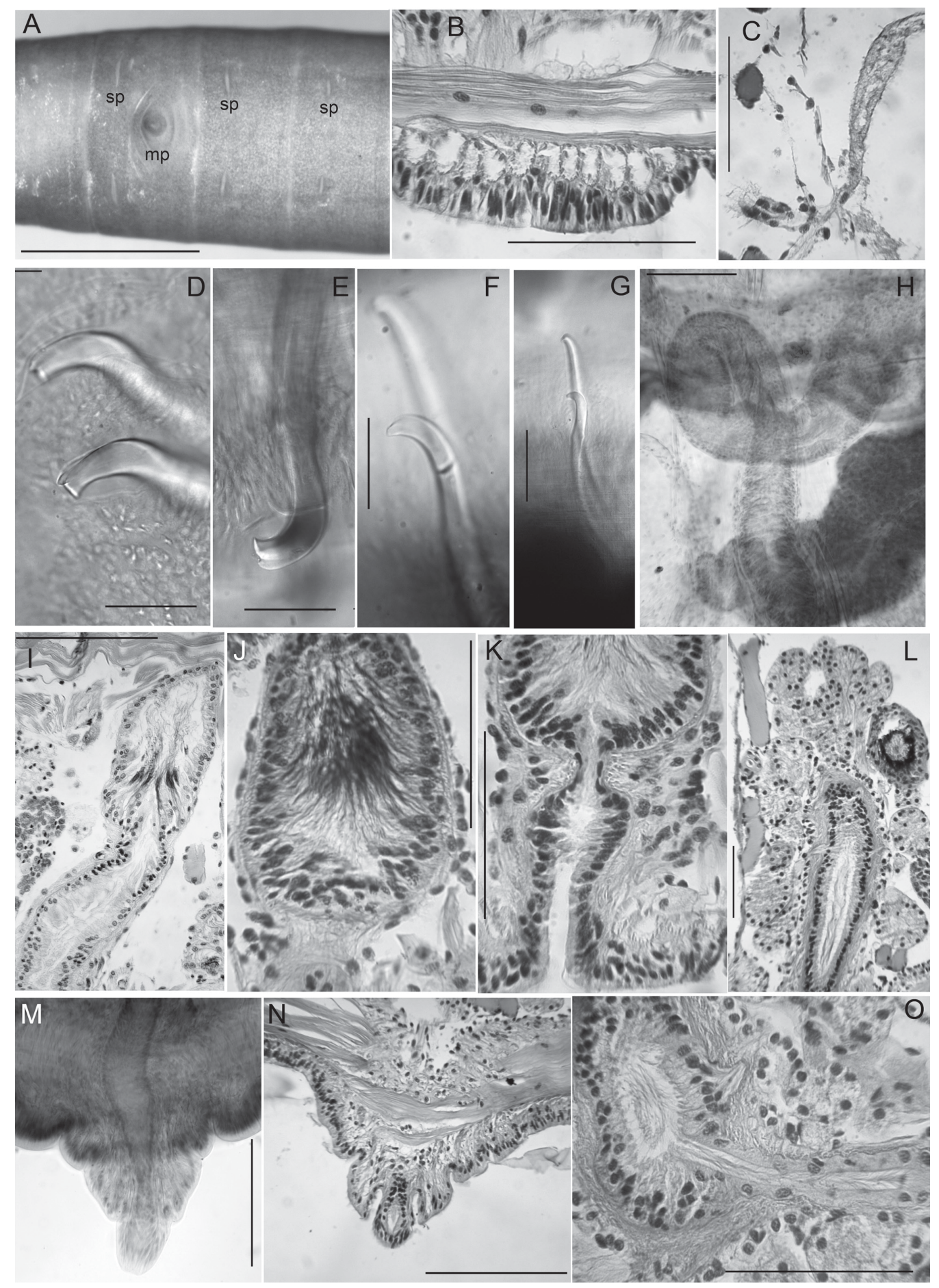

Fig. 5. Kincaidiana smithi Fend \& Rodriguez sp. nov., from the type locality. B-C, I-L, N-O from sagittal sections; D-H, M from dissections. A. Ventral view of an entire worm, stained with hematoxylin, showing positions of genital pores. B. Body wall in segment III, showing longitudinal and transverse muscle layers. C. Nephridial funnel and postseptal expansion. D. Chaetae in V dorsal. E. IV ventral. F-G. Chaetae in posterior segments; (F) is detail of tip, showing slight keel. H. Spermatheca. I. Junction of spermathecal "duct" and "ampulla"; sperm are in the ampullar part. J. Ectal end of spermathecal duct, with sperm lined up along epithelium. K. Spermathecal vestibule and ectal end of duct, with muscular sphincter. L. Atrium with prostate glands. M-N. Penis and male porophore. O. Vas deferens joining atrium near middle. Scale bars: A = $1 \mathrm{~mm}$; B-C, G, J-L, O = $100 \mu \mathrm{m}$; D-F $=50 \mu \mathrm{m} ; \mathrm{H}-\mathrm{I}, \mathrm{M}-\mathrm{N}=200 \mu \mathrm{m}$. 
third is duct-like, 100-130 $\mu \mathrm{m}$ wide, with uneven, columnar epithelium $25-50 \mu \mathrm{m}$ thick, and distinct muscle layer 5-8 $\mu \mathrm{m}$ thick. Ental, ampullar section mostly tubular (about 75-85 $\mu \mathrm{m}$ wide), but may expand to 100-200 $\mu \mathrm{m}$ wide near ental end. Epithelium of ectal, duct-like section of spermatheca may be penetrated by heads of darkly-staining sperm cells which densely fill the lumen (Fig. 5J). Epithelium thinner (about $10 \mu \mathrm{m}$ ) in ental part of ampulla, and lumen wider, containing small amount of unordered, poorly staining sperm. Spermathecae in IX usually largest; those in XI smallest and may lack sperm. Spermathecae may extend posteriad through 1-2 segments (Fig. 4D).

Male pore without obvious glands, but surrounded by diffuse mass of muscle tissue. Single, prosoporous atrium is joined by both (posterior) vasa deferentia near the midpoint; they enter the atrial lumen directly at the junction (Fig. 5O). Atrium narrows ectally within the porophore; the remainder tubular, not divided into distinct regions, extending at least into mid-X (Fig. 4C-D); length 825-1620 $\mu \mathrm{m}$, width 110-130 $\mu \mathrm{m}$, including thick $(12-25 \mu \mathrm{m})$ muscle layer. Atrial muscle layer thickest in ectal part, with fibers unevenly transverse to slightly diagonal, but not lined up (parallel) or in distinct layers; epithelium cuboidal, $10-15 \mu \mathrm{m}$ thick. Ental $1 / 2-2 / 3$ of the atrium covered by thick layer of multicellular prostate glands, $120-190 \mu \mathrm{m}$ high; glands petiolate, broadly pyriform, with many cells (Figs 4E, 5L). Vasa deferentia 1200-1400 $\mu \mathrm{m}$ long, 34-40 $\mu \mathrm{m}$ wide; widest near the atrium (up to 40-48 $\mu \mathrm{m}$ ), where they are covered by a thin muscle layer. Vasa extend posteriorly one or more segments, terminating in elongate, narrowly conical sperm funnels, up to $400 \mu \mathrm{m}$ long.

\section{Remarks}

Both morphology and molecular results (see below) support $K$. smithi sp. nov. as a distinct species, closely related to $K$. hexatheca. Despite the morphological variability of $K$. hexatheca throughout its broad geographic range, $K$. smithi sp. nov. is distinctive in that all specimens from the type locality and a nearby site have a single, median male pore and atrium joined by both of the posterior vasa deferentia. The single, median atrium of $K$. smithi sp. nov. is unusual within the family, but this character appears in both species of Tatriella Hrabě, 1939, as well as in some species of Eclipidrilus Eisen, 1881 (see Fend \& Lenat 2012). As in K. smithi sp. nov., this arrangement does not usually represent a simple loss of one of the male ducts from the normal paired condition. In Eclipidrilus pacificus Fend, 2005, for example, all four vasa deferentia join the median atrium (Fend 2005: fig. 9B). Aside from rare and presumably teratological variation within populations, only Eclipidrilus ithys Brinkhurst, 1998 was described as having either one or two atria (Brinkhurst 1998); but when only one is present, the entire male duct is missing from one side.

Compared with most specimens of $K$. hexatheca, the atrium in $K$. smithi sp. nov. is more elongate, usually entering the post-atrial segment; nevertheless, this occasionally occurs within the range of variation in populations of $K$. hexatheca (Table 2, Fig. 3C). The spermathecal pores are clearly displaced from the ventral chaetae line towards the mid-body line in $K$. hexatheca, while in $K$. smithi sp. nov. the pores are on the chaetal line, anterior to the chaetal bundles (Fig. 1A-B vs 4A). The morphology of the spermathecae is similar to that of $K$. hexatheca; however, they are typically more narrow-elongate, with faint distinction between ampullar and duct portions.

Other characters of $K$. smithi sp. nov. conform closely to those of its congener, $K$. hexatheca. Both have a large, rather cylindrical body, with a ringed proboscis. The chaetal morphology resembles that of typical $K$. hexatheca, and the distribution and orientation of modified anterior chaetae are also similar. Less conspicuous, but nevertheless unusual characters are also shared with K. hexatheca (see Fend 2009): the circular musculature of the body wall, the narrow, dorsally-directed nephridia, and the muscle layer extending along the ectal end of the vasa deferentia. 


\section{Habitat}

The Smith River site is a large (average discharge $>100 \mathrm{~m}^{3} / \mathrm{s}$ ), free-flowing stream with riffle-pool structure and gravel-boulder substrate. Specific conductance was $90 \mu \mathrm{S} \mathrm{cm}^{-1}$ in April $2014(62-150 \mu \mathrm{S}$ $\mathrm{cm}^{-1}$ in 1978-1981, NWIS 2016a). Kincaidiana smithi sp. nov. was only found in a backwater area with some silt deposition. The other collection site was a small roadcut seep, with slow current and some rooted aquatic vegetation. Guts were filled with undetermined organic matter and very fine mineral particles, with diatoms.

Guestphalinus Michaelsen, 1933

\section{Type species}

Dorydrilus (Guestphalinus) wiardi Michaelsen, 1933.

\section{Included species}

Guestphalinus wiardi (Michaelsen, 1933)

Guestphalinus exilis Fend \& Rodriguez sp. nov.

Guestphalinus elephantinus Fend \& Rodriguez sp. nov.

\section{Emended diagnosis (modified from Michaelsen 1933; Cook 1971)}

Medium-sized to large worms with a filiform proboscis. Chaetae two per bundle. Paired testes in VIII and IX, one pair of ovaries in X. Male pores paired in IX, near 9/10. Spermathecal pores paired in IX, anterior to the male pores. Petiolate copulatory glands (= Pubertätsdrüsen in Michaelsen 1933) associated with male and/or spermathecal pores. Male duct semiprosoporous. Penes absent. Atria elongate, cylindrical to club-shaped, ental part loosely covered with multicellular, pyriform prostate glands. Anterior vasa deferentia form a loop in the pre-atrial segment before entering the atrial segment. Paired spermathecae in the atrial segment, anterior to the atria.

\section{Distribution}

Europe and northwestern USA (present study). Guestphalinus wiardi is rarely reported, but is known from subterranean or spring habitats in Germany (Michaelsen 1933; Griepenburg 1941), Slovenia (Hrabě 1973) and Italy (new material used for the present description, see below), with other records from mountain streams in Crimea (Dembitsky 1987).

\section{Remarks}

Among the lumbriculids with a filiform proboscis, Guestphalinus is distinguished from the semiprosoporous species of Rhynchelmis, Eclipidrilus (Premnodrilus) Smith, 1900 and Eremidrilus Fend \& Rodriguez, 2003 by the location of the male pores in IX (instead of X), the spermathecae in the atrial segment, the anterior vasa deferentia entering the pre-atrial segment, and the morphology of the elongate spermathecae. In addition to being prosoporous, the two Kincaidiana species are easily distinguished from Guestphalinus by the presence of spermathecae also in the first two postatrial segments, and by a different type of modified chaetae in several pre-clitellar segments. Uktena is distinguished from other proboscis-bearing lumbriculids by having atria and spermathecae in VIII (rather than IX), in addition to characters unique within the family: spermatophores, a spermathecal copulatory organ, and multiple genital chaetae (Fend et al. 2015).

Guestphalinus was originally described as a subgenus of Dorydrilus Piguet, 1913 (Michaelsen 1933), but was later elevated to generic status (Hrabě 1936, although spelled Questphalinus in that paper). This decision, although considered provisional in the 1936 paper, has been maintained in subsequent literature (Cook 1971; Hrabě 1973; Dembitsky 1987). 
Guestphalinus wiardi (Michaelsen, 1933)

Fig. 6

Dorydrilus (Guestphalinus) wiardi Michaelsen, 1933: 7, figs 1-2.

Questphalinus wiardi - Hrabě 1936: 10; 1973: 45, figs 4-6.

Guestphalinus wiardi - Cook 1968: 281, fig. 2e; 1971: 237. — Dembitsky 1987: figs I-III.

\section{Material examined}

SLOVENIA: a single specimen, sagittally sectioned on 3 slides, near Dornberk (Czech National Museum (Prague), Hrabě collection, 1970-25 I1-3).

ITALY: a sagittally dissected anterior end, Grotta Sulfurea, Frassasi Cave system, Genga/Ancona, 43.401 ${ }^{\circ} \mathrm{N}, 12.966^{\circ}$ E, Marche, Sharmishtha Dattagupta and Jennifer L. Macalady leg., Jun. 2007.

\section{Description of new material and remarks}

Hrabě (1973) described a mature, unmated specimen from Slovenia, with sperm on the male funnels. This specimen from Hrabě's collection is reexamined here, but only the anterior body section was available. The figures in Hrabě (1973: figs 6-7) correspond to photographs 6B and 6C, respectively, in the present paper (note that labels for spermathecal and male pores should be reversed in Hrabě: fig. 6). The Italian specimen is mature, with clitellum from VIII-XIII and sperm in the spermathecae; the anterior 100 segments are represented. Descriptions by Michaelsen (1933) and Hrabě were quite detailed, and were reviewed by Dembitsky (1987); nevertheless, we can add the following remarks based on both specimens.

A pair of lateral blood vessels is visible in posterior segments of the Italian specimen, and some of these have a few blind branches (Fig. 6I). Chaetae in anterior segments are simple-pointed, but tips of most chaetae in posterior segments bear a distinct dorsal groove, which may appear as a small dorsal tooth in lateral view (Fig. 6F).

The anterior vasa deferentia form a loop in the pre-atrial segment (VIII) before penetrating 8/9 and entering IX to join the atrium (Fig. 6A, E, G) in both of our specimens; this unique character was described and illustrated by Michaelsen (1933), but not mentioned in later descriptions. Posterior vasa deferentia do not penetrate septum 9/10. Michaelsen (1933) described and illustrated a greatly expanded posterior sperm funnel extending well into the posterior sperm sacs. Both posterior and anterior male funnels are small in the Slovenian worm (Fig. 6A); they are much larger in the Italian specimen, and the posterior extends back into X (Fig. 6G). Vasa deferentia are very thick (to $50 \mu \mathrm{m}$ ) in the Italian worm, joining the atrium subapically; they join the atrium before the apex in the Slovenian worm, running a short distance under the muscle layer to enter the lumen apically, as described by Dembitsky (1987) for Crimean specimens. Compared with other descriptions, the atrial ampulla appears rather short and ovate in the Slovenian and Italian worms, although the total atrium length (320 and $335 \mu \mathrm{m}$, respectively) and width are similar to those of the Crimean specimens (Dembitsky 1987). Male pores are on a rounded protrusion (referred to as a porophore by Michaelsen 1933), closely behind a groove containing the spermathecal and copulatory gland pores in the Slovenian worm (Fig. 6A-B). Although this structure was also illustrated by Dembitsky (1987: fig. III) it was not seen in our Italian specimen (Fig. 6G). Prostate glands are large (to about $100 \mu \mathrm{m}$ high), petiolate clusters of cells, more similar to fig. 2 in Michaelsen (1933) than to fig. III in Dembitsky (1987).

The large copulatory glands (Fig. 6C, H) are quite similar in structure to the copulatory glands described below in the new Nearctic species, although a distinct muscle layer was not seen at the duct. 

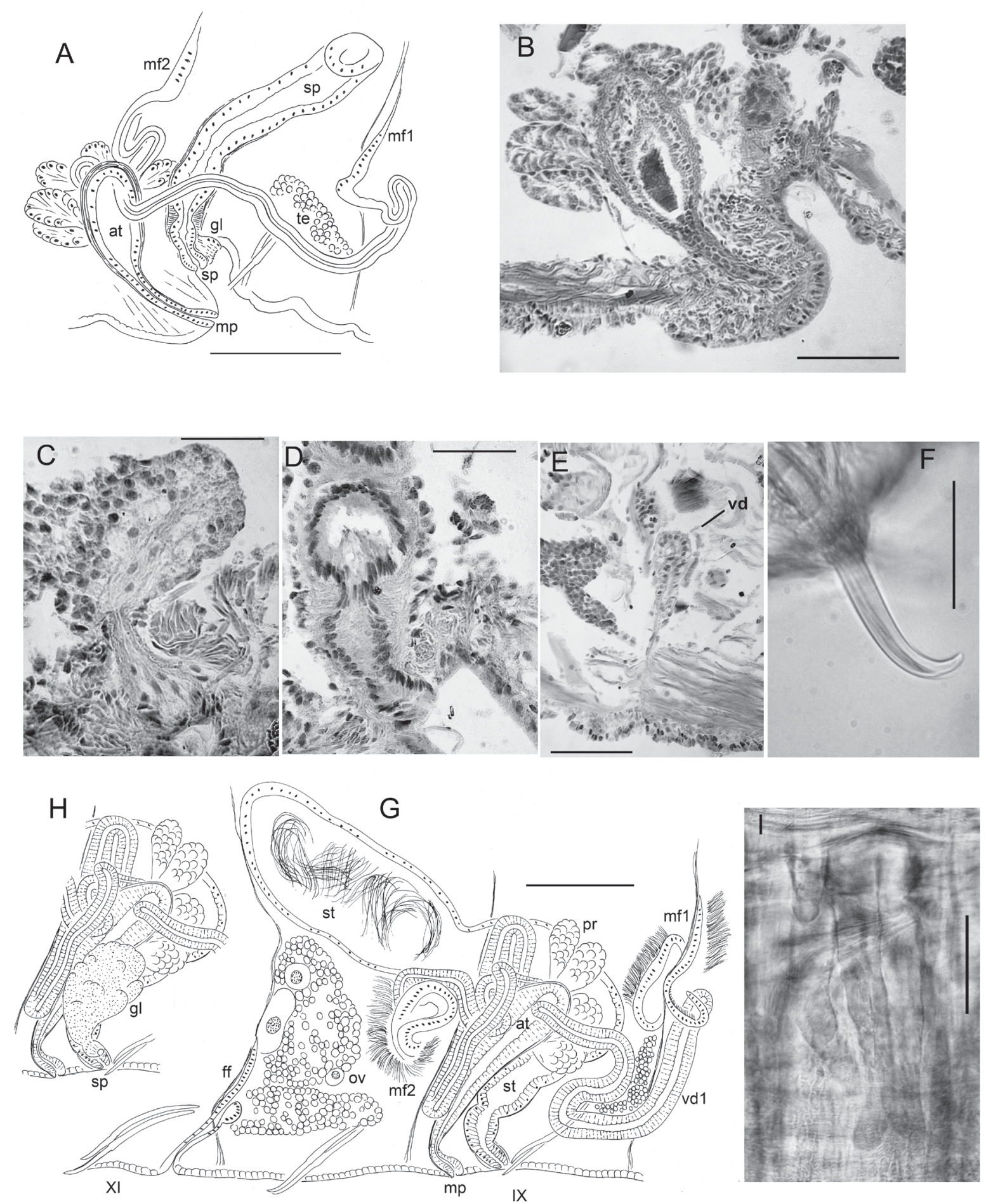

Fig. 6. Guestphalinus wiardi (Michaelsen, 1933); A-E a sectioned worm from Slovenia, Hrabě's collection; F-I, a dissected Italian specimen. A. Male duct and spermatheca in IX, reconstructed from sections; pore from a copulatory gland (not shown) opens next to spermathecal pore. B. Atrium and male porophore. C. Copulatory gland. D. Spermathecal pore and duct. E. Anterior male funnel with vas deferens entering pre-atrial segment. F. Posterior ventral chaeta, showing grooved dorsal tooth. G. Reproductive organs in IX-XI, figure rotated to face to right. H. Detail of G, showing position of copulatory gland, from median view. I. Branched lateral blood vessel in posterior segment. Scale bars: A, G-H $=200 \mu \mathrm{m} ; \mathrm{B}, \mathrm{E}, \mathrm{I}=100 \mu \mathrm{m} ; \mathrm{C}-\mathrm{D}, \mathrm{F}=50 \mu \mathrm{m}$. 
The illustration in Hrabě (1973: fig. 7) is similar to ours. The slight difference in placement (adjacent to the spermathecae in both of our specimens), compared with Michaelsen's material (at the ventral chaetae), suggests that the position of these glands may be variable, as in Guestphalinus exilis Fend \& Rodriguez sp. nov. (see below). Their occurrence may also vary with stage of reproductive development, as Dembitsky (1967) was unable to find these glands in the Crimean specimens, attributing their absence to possible resorption.

The spermatheca is not clearly differentiated into duct vs ampullar sections, although there is a sphincterlike constriction, with thickened circular muscles near the pore of the Slovenian worm (Fig. 6D). The female funnel is clearly visible only in the Italian worm (Fig. 6G), where it appears to penetrate the posterior septum 10/11 (the plesiopore condition), as in the illustration in Michaelsen (1933). Guestphalinus was the only lumbriculid genus considered by Brinkhurst (1989: character 16) to have plesiopore female ducts, in common with Haplotaxis, one of the outgroup taxa in that analysis. However, this character has not been observed in G. elephantinus sp. nov. nor in G. exilis sp. nov., where female pores appear to be intersegmental (see below, Fig. 12Q). Plesiopore female ducts appear to be unusual in the Lumbriculidae (Brinkhurst 1989; Fend \& Ohtaka 2004), but they may simply have escaped notice in other species descriptions. The exact position of the septum may be difficult to define, as muscle fibers from septa may join the body wall on either side of the female funnel.

Guestphalinus exilis Fend \& Rodriguez sp. nov. urn:1sid:zoobank.org:act:37A5A3E0-3DC2-4D24-84AC-62E21131E70E

Figs 7-9

\section{Etymology}

Derived fom the Latin word 'exilis' (small), with reference to G. elephantinus sp. nov. (see below) and to the name of the extinct Californian pygmy mammoth Mammuthus exilis (Stock \& Furlong, 1928).

\section{Material examined}

Holotype

UNITED STATES OF AMERICA: a dissected specimen, slide-mounted in Canada balsam, California, Shasta County, Squaw Creek at Chirpchatter Camp, deep riffle, gravel patches in cobble bottom, 6 May 2012, S. Fend leg. (USNM 1422283).

Paratypes (all collected by S. Fend at the type locality)

UNITED STATES OF AMERICA: 1 dissected on 2 slides, 19 Apr. 2010 (USNM 1422284); 1 dissected, 17 May 2010 (USNM 1422285); 1 dissected, 6 May 2012 (CASIZ 220935); 1 whole mount, 17 May 2010 (CASIZ 220936); 1 sagittally sectioned, 17 May 2010 (CASIZ 220938); a whole mount, immature but with gonads (DNA voucher), 19 Apr. 2010 (CASIZ 220937); 2 dissected on slides, 17 May 2010 (MNCN 16.03/3100-16.03/3101).

\section{Additional material}

UNITED STATES OF AMERICA: CALIFORNIA: 2 sagittal sections, 3 dissected, 4 whole mounts (all immature or partially mature), Shasta County, Squaw Creek at Chirpchatter Camp, 17 Jun. 1996, S. Fend leg.; 1 dissected (partially mature), same locality as preceding, 19 Apr. 2010, S. Fend leg.; 4 dissected (1 mature), 8 whole mounts (immature), several in alcohol, same locality as preceding, 17 May 2010, S. Fend leg.; 1 dissected (mature), several immature in alcohol, same locality as preceding, 6 May 2012, S. Fend leg.; 2 whole mounts (partially mature), Humboldt County, South Fork Eel River at Elk Creek, 24 Jun. 2001, S. Fend leg.; 1 whole mount (partially mature), Mendocino County, Garcia 
River, 23 Mar. 1996, W. Fields leg.; 1 whole mount (immature, with small gonads), Colusa County, Stony Creek at Stonyford, 4 Nov. 2002, S. Fend leg.

\section{Molecular data}

COI, $28 \mathrm{~S}$ and $16 \mathrm{~S}$ sequences correspond to a topotypic paratype (see Table 1 for details).

\section{Description}

Specimens from the type locality: body measurements in Table 3. Prostomium rounded to nearly conical; filiform proboscis 0.9 to $2.1 \mathrm{~mm}$ long, diameter at midpoint $0.1-0.15 \mathrm{~mm}$, appearing ringed with multiple shallow constrictions (Figs 7A-C, 9A). Body segmentation not strong in external view; secondary annulation a narrow anterior ring in IV-IX, weak in post-clitellar segments. Clitellum from VIII to XII or mid-XIII, absent ventrally in IX in the area surrounding male and spermathecal pores (Figs 7B, 9A).

Chaetae paired, in 4 bundles in each segment, beginning in II. Chaetal measurements given in Table 3. Chaetae in II bluntly simple-pointed to shallowly notched, directed anteriorly (Figs 7E-G, 9B-C, E); these chaetae slightly sigmoid, with distal nodulus; within each bundle, lateral chaeta slightly longer than the median, with more distal nodulus. Posterior to II, chaetae sigmoid, mostly simple pointed, with nodulus about $1 / 3$ of distance from tip; perpendicular to body axis or posteriorly directed; chaetae in III slightly shorter, but those in more posterior segments similar in length to those in II. Chaetae in posterior segments may have a slight dorsal keel (Fig. 9D). Ventral chaetae absent in IX in mature and post-reproductive worms.

Epidermis in anterior segments $12-24 \mu \mathrm{m}$ thick, in clitellum $30-50 \mu \mathrm{m}$, posteriorly $5-10 \mu \mathrm{m}$. In preclitellar segments, circular muscle layer of body wall arranged in a series of transverse bands (cf. Fig. 12K), 10-15 $\mu \mathrm{m}$ thick; posteriorly a simple layer about $5 \mu \mathrm{m}$ thick. Longitudinal muscle layer $50-60 \mu \mathrm{m}$ thick. Brain in the peristomium, lateral lobes rounded. Pharynx begins dorsally and laterally in II, ventrally in III, extending through IV. Pharyngeal glands in IV to VI or VII; on each side, three lobes (dorsal, lateral and median) (Fig. 9G) broadly connected at posterior septum of each segment and extending anteriorly, joining corresponding lobe in previous segment by a thin extension. No abrupt division between esophagus and intestine. Chloragogen cells cover the gut usually beginning in VII; in the most posterior segments many free eleocytes present in the coelomic cavity (Fig. 9H).

First nephridia usually on 6/7, absent in VIII-XI, usually paired on 11/12, occuring irregularly in posterior segments. Each nephridium with small anteseptal funnel; granular postseptal expansion elongate to ovate (length 130-250 $\mu \mathrm{m}$, diameter $40-80 \mu \mathrm{m}$ ), directed posteriad or somewhat dorsad (Fig. 9I); convoluted efferent duct may pass through one or more adjacent (anterior or posterior) segments, ventral or ventrolateral to the gut, usually near the ventral blood vessel, terminating in a short ectal branch to a simple nephridiopore anterior to the ventral chaetae; indistinct vesicle at the pore in some specimens.

Dorsal blood vessel passes under brain: two forks pass around the pharynx and join in IV, forming the ventral vessel. Dorsal vessel free anteriorly, closely appressed to top of gut posterior to VI or VII. Ventral vessel separate from gut, but 2-3 short vessels join it to the perivisceral sinus in each segment posterior to about VII. One pair of commissural vessels in anterior segments; those in II-VI (or VII) long and sinuous, extending through most of originating segment; those in VIII to XII (or XIV) restricted to posterior part of the segment, but a posterior loop from those in IX and X may enter sperm and egg sacs. No lateral blood vessels observed behind about segment XIV. Perivisceral sinus begins in about VII.

Genital field covers ventral side of IX, flattened or slightly concave in preserved, mature worms. Male and spermathecal pores paired in IX. Male pores near posterior intersegmental groove (Fig. 7A-B) and inside lines of ventral chaetae; spermathecal pores in line with, and in front of male pores, about level 

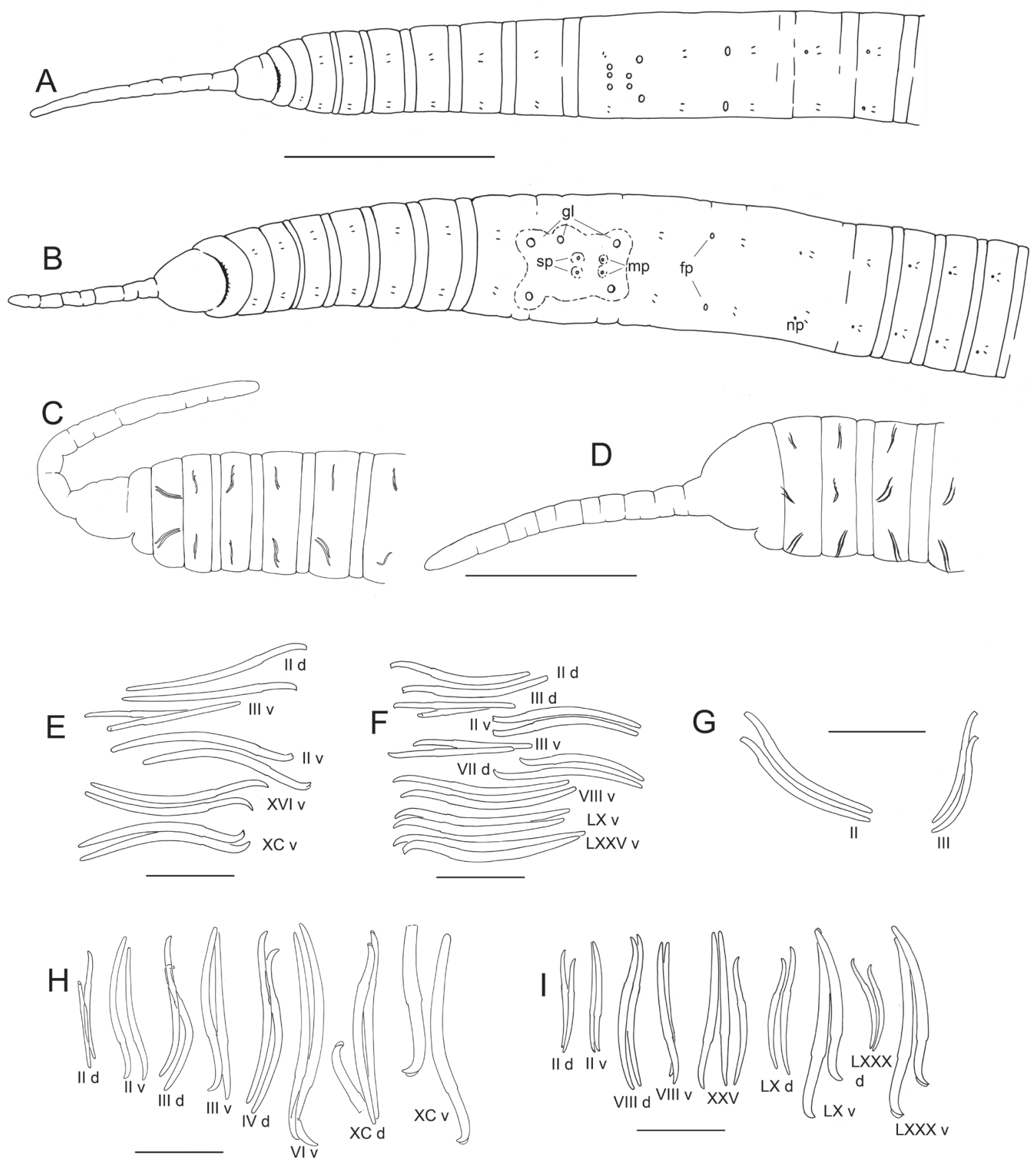

Fig. 7. Guestphalinus exilis Fend \& Rodriguez sp. nov., external characters. A-C, E-G from Squaw Creek, CA (the type locality); D, H from South Fork Eel River, CA; I from Stony Creek, CA. A-B. Ventral views of two worms, showing positions of genital pores: A is partially-mature, with 3 glands opening around male and spermathecal pores; B is from a reproductively-mature worm, dashed line encloses the non-clitellar genital field with 5 glands opening around spermathecal and male pores. C-D. Anterior end, showing orientation of chaetae. E-G. Selected chaetae from typical specimens; G shows relative position of dorsal chaetae in II and III. H-I. Selected chaetae from partially-mature worms. Chaetae are numbered by segment (Roman numerals), followed by "d" (dorsal) or "v" (ventral). Scale bars: A-B = $2 \mathrm{~mm} ; \mathrm{C}-\mathrm{D}=1 \mathrm{~mm} ; \mathrm{E}-\mathrm{I}=100 \mu \mathrm{m}$. 
with dorsal chaetal bundles (ventral chaetae absent in IX). Female pores paired, on chaetal line at intersegmental groove 10/11. Secretory openings of copulatory glands in IX, small and circular areas, lateral to genital pores, and either in front of or behind them. Paired testes on anterior septa in VIII and IX may be large, extending through anterior half of segment; ovaries in X, reaching to posterior septum, or into XI. Sperm sacs extending back to XIV-XVII in mature worms, egg sacs as far as XV-XVII.

Spermathecae to over $2000 \mu \mathrm{m}$ long in mated worms, nearly tubular, with two, weakly differentiated sections, both containing sperm. Ectal, duct-like section gradually expanding to form ental ampulla; ampulla may be folded within IX (both in unmated or mated specimens) or extending into X-XII. Ectally, spermatheca passes through a short $(12 \mu \mathrm{m})$, narrow constriction within ring of muscle fibers (Figs 8A-B, 9J) and terminates in a shallow epidermal infolding, about 70-110 $\mu \mathrm{m}$ deep. Duct-like section (80-100 $\mu \mathrm{m}$ diameter) with irregular, columnar epithelium (up to 40-45 $\mu \mathrm{m}$ high); dense sperm may be lined up along epithelium (Fig. 9K); very thin outer muscle layer about $2 \mu \mathrm{m}$ thick. Ampullalike section nearly tubular, diameter about $100 \mu \mathrm{m}$ for much of its length, but may be entally expanded to over $200 \mu \mathrm{m}$ (Figs 8A, 9L), with thinner epithelium and wider lumen containing sparse spermatozoa.

Typically, 3-6 stalked copulatory glands are associated with genital pores in mature and nearly-mature worms (Fig. 8A-C); they are absent at early stages of reproductive development. Glands are a pyriform cluster of granular, petiolate cells 160-300 $\mu \mathrm{m}$ long (Fig. 9M-N), sometimes appearing as a group of smaller clusters. Conjoined cell extensions of the gland are constricted by a ring of circular muscle fibers and then surrounded by thin epithelium before opening in a round secretory surface (to $50 \mu \mathrm{m}$ diameter) on the body wall.

Anterior and posterior male funnels about equal in size, to $240 \mu \mathrm{m}$ high; anterior pair rather flat on septum 8/9; posterior pair on $9 / 10$, but usually directed back into X; both pairs functional, with sperm when fully mature. Anterior vas deferens extends into VIII (Figs 8A-C, 9O), forming a convoluted mass, then penetrates $8 / 9$, running along ventral body wall to near the male pore, then follows atrium to near the ental end, joining the atrium apically. Length of anterior vasa deferentia to $2600 \mu \mathrm{m}$, width 36-50 $\mu \mathrm{m}$. Posterior vas deferens forms a compact, convoluted mass in posterior IX, then follows atrium within the sperm sac, joining it at or near the apical end. Length of posterior vasa over $2000 \mu \mathrm{m}$, width 38-46 $\mu \mathrm{m}$. Vasa deferentia histologically similar throughout, with ciliated, non-glandular epithelium.

Atria of mature worms usually extend back into X or XI; in nearly-mature worms they may be entirely in IX. Atria petiolate in mature worms (Fig. 8A-B); a short ectal duct (150 $\mu \mathrm{m}$ long) has thick, columnar epithelium and a thin (to $2 \mu \mathrm{m}$ ) muscle coat; no distinct penis, although duct may be somewhat expanded at male pore, with thickened epithelium (Figs 8B, 9Q). An abrupt transition from the atrial duct to the tubular or sacciform atrial ampulla. Ampulla length to $1060-1105 \mu \mathrm{m}$, width $130-150 \mu \mathrm{m}$, thin-walled (5-8 $\mu \mathrm{m})$ with cuboidal epithelium and wide lumen (Figs 8A, 9P); clusters of prostatic cells, 70-140 $\mu \mathrm{m}$ long, sparsely cover the atrial ampulla. In nearly-mature, unmated worms, atria tubular (Fig. 8C); ampulla and duct not greatly differentiated; prostates small but appear more densely packed than in mated worms.

Eel River, Stony Creek and Garcia River, northern California: The few, partially-mature specimens from these localities are tentatively assigned to Guestphalinus exilis sp. nov. based on the ringed proboscis, the chaetae, and gonads in VIII, IX and X. They differ from the type diagnosis in that chaetae in II are smaller than other anterior chaetae, and simple-pointed (but oriented forward, as in the type locality population). Ventral chaetae in posterior segments distinctly keeled and larger than corresponding dorsals (Fig. 7H-I). As in typical G. exilis sp. nov., specimens from Eel River have semiprosoporous male ducts, with vasa deferentia joining atrium apically and the anterior vas deferens penetrating 8/9 (Fig. 8D). Spermathecal and male pores are behind ventral chaetae of IX and 5 large copulatory glands surround the genital pores. One specimen has an additional, developing spermatheca on one side, in X. 

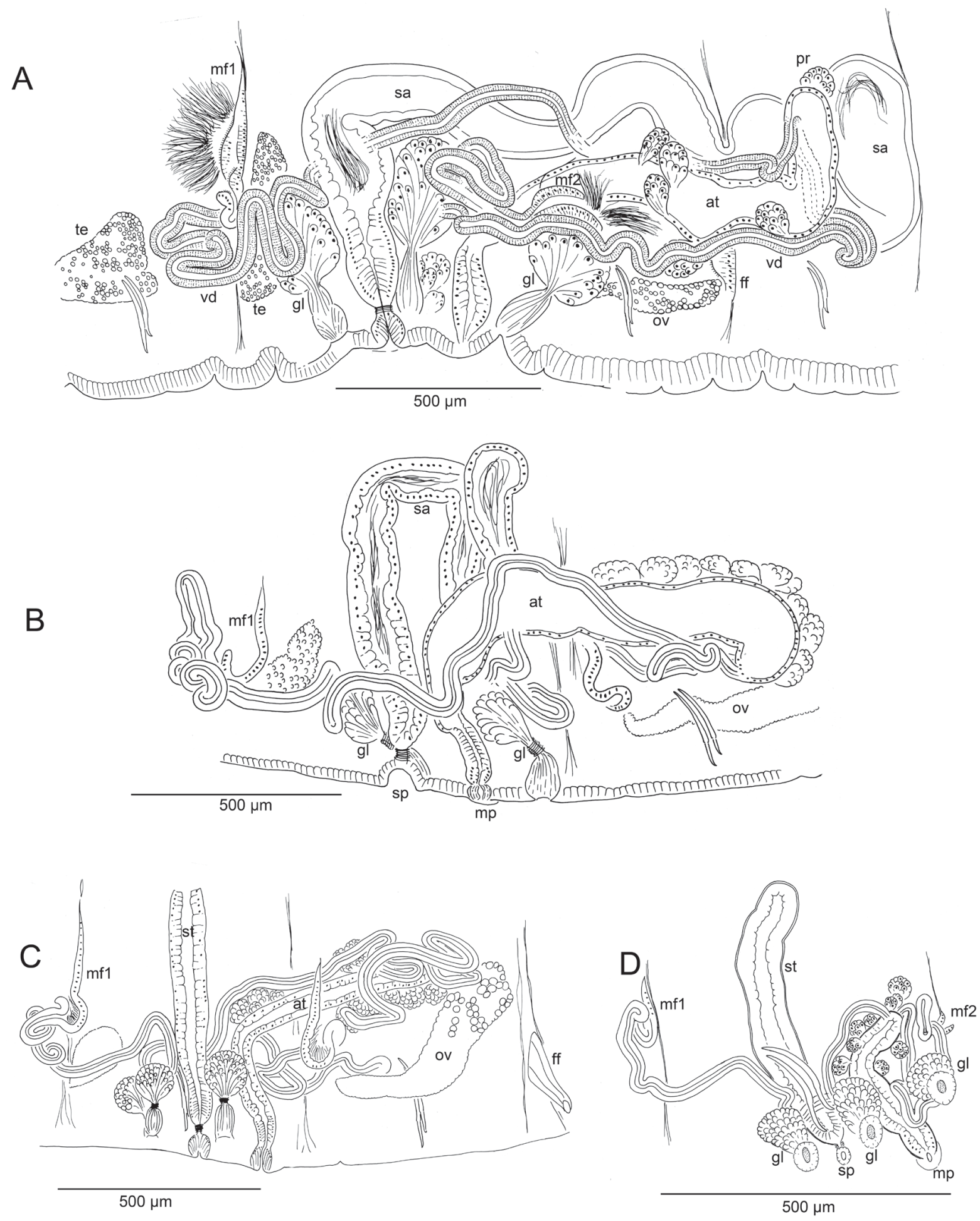

Fig. 8. Guestphalinus exilis Fend \& Rodriguez sp. nov., reproductive structures, all oriented with anterior end to left. A-C from Squaw Creek (the type locality), D from the South Fork Eel River A. Segments VIII-XI of a mature worm, showing reproductive organs; anterior vas deferens broken at spermatheca. B. Segments IX-X of a recently-mated worm; spermathecal ampulla not yet developed; atrium expanded. C. Segments IX-X of a partially-mature worm; atrium and spermathecae tubular, but copulatory glands well-developed; ental end of spermatheca missing. D. Segment IX of a partially-mature worm; glands well developed; atrium and spermatheca small, tubular. 

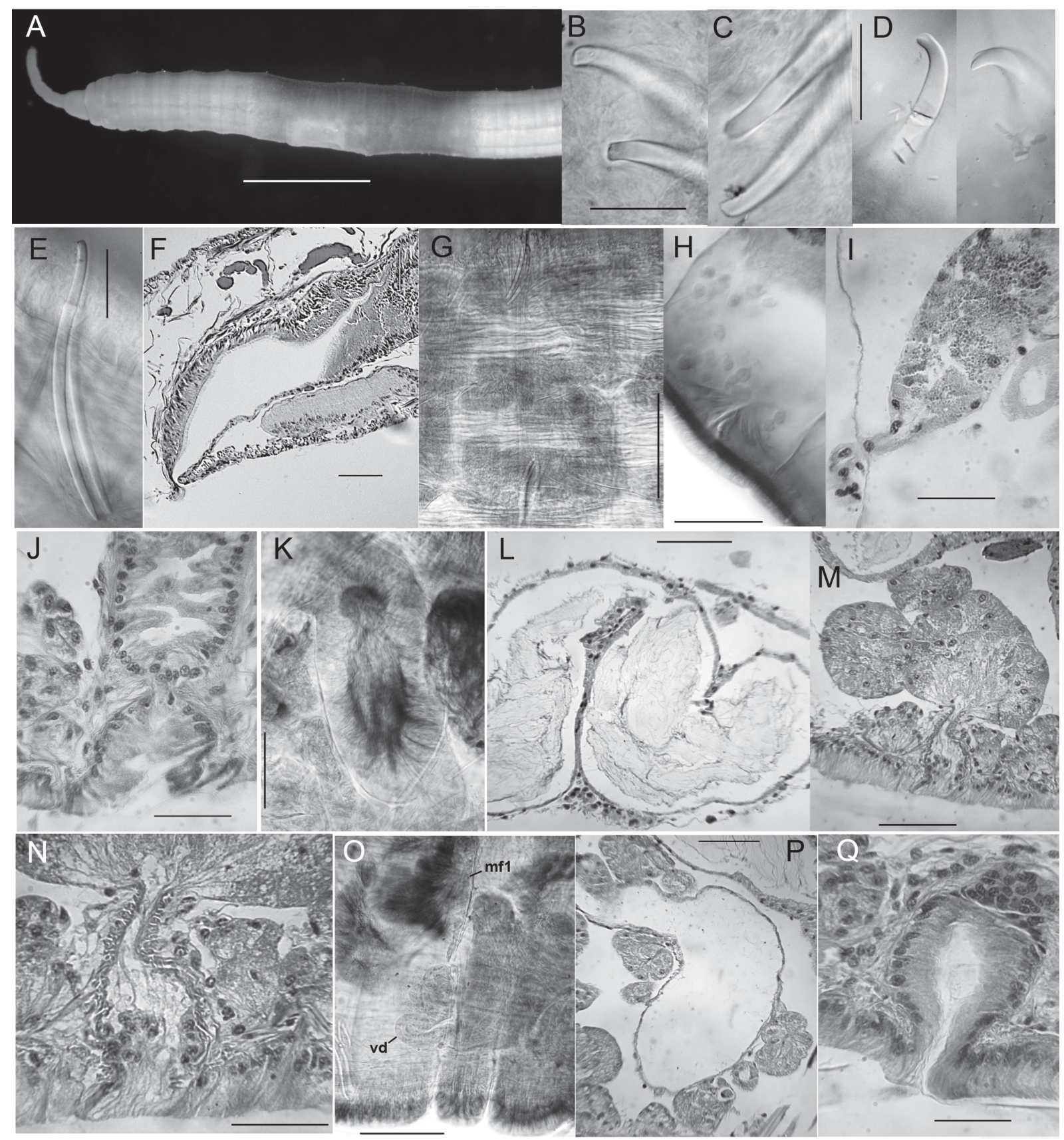

Fig. 9. Guestphalinus exilis Fend \& Rodriguez sp. nov., from Squaw Creek (the type locality); F, I-N, $\mathrm{P}-\mathrm{Q}$ from sagittal sections. A. A complete worm, anterior end, lightly stained with hematoxylin, showing clitellum and genital field. B. Tips of chaetae in II dorsal. C. Chaetae in II ventral. D. Tips of chaetae in two posterior segments, showing dorsal keel. E. Chaetae in II dorsal. F. Pharynx. G. Pharyngeal glands from a whole mount, 3 lobes facing anteriad (to left). H. Eleocytes, in a posterior segment. I. Nephridial funnel (left) and postseptal expansion. J. Spermathecal pore and constricted ectal end of duct. K. Spermathecal ampulla, ectal part, with sperm penetrating epithelium. L. Spermathecal ampulla, ental part with weakly-staining sperm. M. Ventral copulatory gland. N. Pore of copulatory gland. O. Anterior vas deferens protruding into VII (to left), with male funnel on 8/9. P. Expanded atrial ampulla with prostates. Q. Male pore. Scale bars: A $=2 \mathrm{~mm}$; B-E, H-J, N, Q $=50 \mu \mathrm{m} ; \mathrm{F}-\mathrm{G}, \mathrm{K}-\mathrm{M}$, $\mathrm{O}-\mathrm{P}=100 \mu \mathrm{m}$. 


\section{Remarks}

Guestphalinus exilis sp. nov. from western North America resembles the Palearctic G. wiardi in characters considered diagnostic for the genus (see above). Compared with G. wiardi, G. exilis sp. nov. has modified chaetae in II, a much larger, sacciform atrium, and more copulatory glands; the male pore was never strongly protruding (Fig. 6B vs Fig. 8A-B). The reproductive organs of G. exilis sp. nov. are morphologically similar to those of G. elephantinus sp. nov. (see below); both lack a distinct male porophore or penis, although the atrial duct may be somewhat expanded at the male pore, with thickened epithelium, suggesting that lining cells may be protrusible (Figs 9Q, 12M, O) as "type-2 penes" (temporary structures formed by extruded lining cells of the male duct, see Rodriguez \& Giani 1994: fig. 17D-F).

Molecular results strongly suggest more than one Nearctic species (see below). Both new Guestphalinus species present distinctive chaetal morphotypes, and these chaetal characters are therefore used here as main diagnostic characters. Nevertheless, there is some variation among populations assigned to both basic morphotypes. In segment II chaetae of typical (from Squaw Creek) G. exilis sp. nov. are slightly modified relative to those in other segments. In most Squaw Creek specimens the chaetae appear slightly notched, slightly larger than those in III, and a little shorter than those in middle segments (Table 3). In specimens from two other California sites, chaetae in II are simple-pointed and smaller than those in III - and thus similar to most other lumbriculids. These are provisionally assigned to G. exilis sp. nov., based on the limited and only partially-mature available material. Partially developed reproductive organs (Fig. 8D) clearly indicate that the Eel River specimens belong to Guestphalinus as defined here. The single specimens from Stony Creek and the Garcia River, although immature, have gonads in VIII-X, distinguishing them from other proboscis-bearing lumbriculid genera in the region (e.g., Kincaidiana, Rhynchelmis and Eremidrilus).

\section{Habitat}

The type locality is Squaw Creek, a tributary to the Sacramento River, in northern California; the collection site is a $5^{\text {th }}$ order riffle-pool stream with gravel-cobble sediment (U.S.D.A. 1999). The type series was found only at the lower end of a single riffle, and no additional material has been found at other sites within the stream. Other oligochaetes were collected throughout the stream; dominant species were Mesenchytraeus pedatus Eisen, 1904 and Rhyacodrilus clio Rodriguez \& Fend, 2013 (also the type locality for $R$. clio). The four streams where G. exilis sp. nov. was collected were similar in size and sediment characteristics, and are coldwater streams, supporting salmonid fishes. The species was usually found in patches of finer gravel within cobble-boulder riffles. Specific conductance at the Squaw Creek and Eel River sites (April 2014) was 265 and $250 \mu \mathrm{S} \mathrm{cm}^{-1}$, respectively. Earlier measurements at a downstream site on Squaw Creek (Rettig \& Bortleson 1983) gave temperatures from 13.5 to $22.5^{\circ} \mathrm{C}$ and a specific conductance of 109-261 $\mu \mathrm{S} \mathrm{cm}^{-1}$. Visits to the type locality from July to September did not produce any specimens of $G$. exilis sp. nov. The sporadic occurrence and patchy distribution suggest that, like $G$. wiardi, they may also be primarily groundwater or hyporheic worms that only occasionally show up in surface collections.

Guestphalinus elephantinus Fend \& Rodriguez sp. nov. urn:1sid:zoobank.org:act:A30D385C-06C9-438E-AAFC-1F145905B74F

Figs $10-12$

“Guestphalinus sp. nov." - Zhou et al. 2010: 381, figs 1-6 (sequenced, but not morphologically described; voucher SMNH 105628). 
Table 3. Descriptive measurements (mean, range, and n) for different populations of G. exilis Fend \& Rodriguez sp. nov. and G. elephantinus Fend \& Rodriguez sp. nov. Measurements of "nodulus" refer to the proportional distance from the tip of the chaeta (i.e., " 0.5 " means the nodulus is at the midpoint of the chaeta).

\begin{tabular}{|c|c|c|c|c|c|c|c|c|c|c|c|}
\hline & 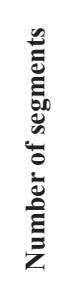 & 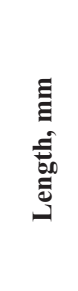 & 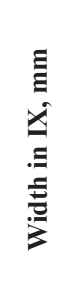 & 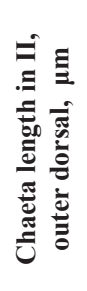 & 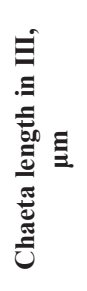 & 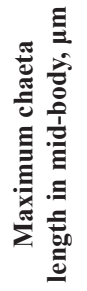 & 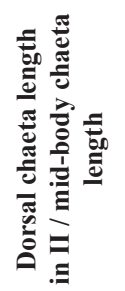 & 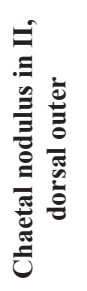 & 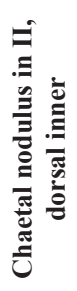 & 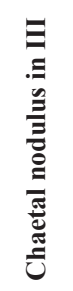 & 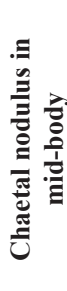 \\
\hline \multicolumn{12}{|c|}{ G. exilis Fend \& Rodriguez sp. nov.: Squaw Creek, California, USA (type locality) } \\
\hline Mean & 101 & 35.5 & 0.89 & 182 & 157 & 204 & 0.91 & 0.23 & 0.23 & 0.32 & 0.31 \\
\hline $\max$ & 123 & 54 & 1.17 & 218 & 182 & 226 & 1.20 & 0.27 & 0.28 & 0.38 & 0.34 \\
\hline $\min$ & 78 & 19 & 0.67 & 134 & 113 & 170 & 0.76 & 0.19 & 0.19 & 0.24 & 0.25 \\
\hline $\mathrm{n}$ & 16 & 22 & 24 & 21 & 18 & 17 & 16 & 16 & 16 & 14 & 12 \\
\hline \multicolumn{12}{|c|}{ G. elephantinus Fend \& Rodriguez sp. nov.: Olympic Peninsula, Washington, USA (including type locality) } \\
\hline Mean & 117 & 46.3 & 0.76 & 355 & 142 & 207 & 1.73 & 0.15 & 0.23 & 0.32 & 0.35 \\
\hline $\max$ & 131 & 61 & 1.11 & 510 & 180 & 256 & 2.42 & 0.18 & 0.26 & 0.44 & 0.41 \\
\hline $\min$ & 92 & 26 & 0.62 & 252 & 106 & 165 & 1.20 & 0.1 & 0.2 & 0.23 & 0.28 \\
\hline $\mathrm{n}$ & 36 & 52 & 58 & 52 & 44 & 43 & 42 & 52 & 50 & 43 & 43 \\
\hline \multicolumn{12}{|c|}{ G. elephantinus Fend \& Rodriguez sp. nov.: other northwestern sites, USA (Satsop River, Washington; Euchre Creek, Oregon) } \\
\hline Mean & 131 & 47.1 & 0.93 & 701 & 280 & 230 & $\mathbf{3 . 0 7}$ & 0.13 & 0.21 & 0.24 & 0.36 \\
\hline $\max$ & 145 & 54 & 1.3 & 916 & 372 & 276 & 3.32 & 0.14 & 0.25 & 0.3 & 0.4 \\
\hline $\min$ & 116 & 42 & 0.7 & 554 & 154 & 182 & 2.95 & 0.12 & 0.19 & 0.2 & 0.29 \\
\hline $\mathrm{n}$ & 2 & 3 & 5 & 6 & 6 & 5 & 5 & 6 & 6 & 6 & 5 \\
\hline \multicolumn{12}{|c|}{ G. elephantinus Fend \& Rodriguez sp. nov.: Peavine Ridge spring, Oregon, USA } \\
\hline Mean & 114 & 42.6 & 0.67 & 423 & 162 & 236 & 1.79 & 0.18 & 0.25 & 0.37 & 0.37 \\
\hline $\max$ & 128 & 54 & 0.8 & 458 & 187 & 253 & 1.91 & 0.19 & 0.27 & 0.39 & 0.4 \\
\hline $\min$ & 84 & 33 & 0.53 & 360 & 154 & 223 & 1.58 & 0.16 & 0.22 & 0.35 & 0.35 \\
\hline $\mathrm{n}$ & 8 & 10 & 10 & 9 & 9 & 9 & 9 & 9 & 9 & 8 & 9 \\
\hline \multicolumn{12}{|c|}{ G. elephantinus Fend \& Rodriguez sp. nov.: Guadalupe and Alamitos Creeks, California, USA } \\
\hline Mean & 119 & 40.4 & 0.78 & 489 & 251 & 213 & 2.38 & 0.12 & 0.22 & 0.21 & 0.37 \\
\hline $\max$ & 135 & 74 & 1.17 & 794 & 437 & 316 & 3.28 & 0.14 & 0.29 & 0.28 & 0.41 \\
\hline $\min$ & 88 & 18 & 0.49 & 372 & 187 & 114 & 1.58 & 0.11 & 0.2 & 0.15 & 0.33 \\
\hline $\mathrm{n}$ & 6 & 7 & 9 & 11 & 11 & 11 & 11 & 11 & 11 & 11 & 11 \\
\hline
\end{tabular}

\section{Etymology}

Based on the fanciful and homoplasious similarity to an elephant (proboscis and anteriorly-directed "tusks").

\section{Material examined}

\section{Holotype}

UNITED STATES OF AMERICA: a dissected specimen, slide-mounted in Canada balsam, Washington, Jefferson County, Shale Creek at Clearwater Creek Road, 4 Jun. 2003, S. Fend leg. (USNM 1422286). 
Paratypes (all from the Clearwater River drainage, on Olympic Peninsula, Washington) UNITED STATES OF AMERICA: 1 dissected (post-reproductive), Jefferson County, Clearwater River at Upper Clearwater Camp, 27 Apr. 2004 (USNM 1422287); 1 dissected (post-reproductive), same data as preceding (CASIZ 220932); 1 dissected (post-reproductive), Hurst Creek near Clearwater River, 25 Apr. 2004 CASIZ 220933); 1 whole mount, immature but with gonads (DNA voucher), from type locality, 4 Jun. 2003 (CASIZ 220934); 1 dissected (post-reproductive), Clearwater River at Upper Clearwater Camp, 27 Apr. 2004 (MNCN 16.03/3098); 2 partially-mature whole mounts on 1 slide, Shale Creek at Clearwater Creek Road, 4 Jun. 2003 (MNCN 16.03/3099).

Additional material (typical specimens)

UNITED STATES OF AMERICA: WASHINGTON, Jefferson County (all from the Clearwater River drainage, on Olympic Peninsula): 2 dissected (mature, reproductive organs slightly resorbed), Bull Creek near Clearwater River, 2 Apr. 2016; 2 whole mounts (immature, with small gonads), Clearwater River at Upper Clearwater Camp, 4 Jun. 2003; 4 dissected, (immature or post-reproductive), same locality as preceding, 27 Apr. 2004; 1 dissected and 16 whole mounts, several in alcohol (all immature or partially mature), Clearwater River at Copper Mine Bottom Camp, 25 Apr. 2004; 8 whole mounts (immature or partially mature), Shale Creek at Clearwater Creek Road, 4 Jun. 2003; 4 whole mounts (immature), same locality as preceding, 14 Apr. 2010; 5 whole mounts (immature), Hurst Creek, 25 Apr. 2004.

\section{Other sites}

UNITED STATES OF AMERICA: WASHINGTON: 1 dissected (slightly post-reproductive), 2 whole mounts (post-reproductive), Grays Harbor County, Middle Fork Satsop River, 27 Apr. 2004, S. Fend leg.; 2 whole mounts (1 nearly mature), Columbia County, Tucannon River below Turner Road, 29 Jul. 2011, Uttam Rai leg. - OREGON: 1 sagittal section, 1 transverse section, 3 dissected, 6 whole mounts (dissected and sectioned nearly mature, others with gonads),Yamhill County, spring at Peavine Ridge near McMinnville, 5 Dec. 1999, S. Fend leg.; 1 whole mount (immature, with gonads), Curry County, Mule Creek at upstream bridge, near Rogue River, 7 Jun. 2003, S. Fend leg.; 1 dissected (immature, with gonads), Curry County, Euchre Creek near mouth, 20 May 2013, S. Fend leg. - CALIFORNIA: 1 whole mount (immature), Santa Clara County, Alamitos Creek above Almaden Reservoir, 1 May 1997, S. Fend leg.; 1 whole mount (immature), Santa Clara County, Guadalupe Creek above Guadalupe Reservoir, below Rincon Creek, 3 Apr. 2001, S. Fend leg.; 1 dissected (mature) and 2 whole mounts (partially mature), same locality as preceding, 25 Mar. 2007, S. Fend leg.; 1 whole mount (immature), same locality as preceding, 10 Feb. 2008, S. Fend leg.; 1 whole mount (immature), same locality as preceding, 5 Dec. 2009, S. Fend leg.; 1 dissected (post-mature), same locality as preceding, 20 Jun. 2011, S. Fend leg.

\section{Molecular data}

COI, 28S and 16S sequences are based on specimens from Shale Creek and Clearwater River, Washington (details in Table 1). An additional ITS sequence (GenBank acc. no. GU592364) corresponds to the Clearwater River voucher SMNH105628. A topotypic voucher is included in the type series (see above). Both COI sequences for G. elephantinus sp. nov. are identical.

\section{Description}

\section{Specimens from the Clearwater River drainage, Olympic Peninsula, Washington}

Description of somatic characters is based on mature or partially-mature (with gonads) worms from Clearwater River, Hurst Creek, Shale Creek and Bull Creek. Reproductive organs are described from the only fully-mature specimen (the holotype), from Shale Creek, and supplemented with 9 postreproductive specimens with partially-resorbed organs from nearby sites

Body form and segmentation as described for G. exilis sp. nov. (see above), measurements given in Table 3. Length of proboscis 0.9-2.6 mm (Figs 11A, 12A), clitellum from VIII to XII in the mature worm. 

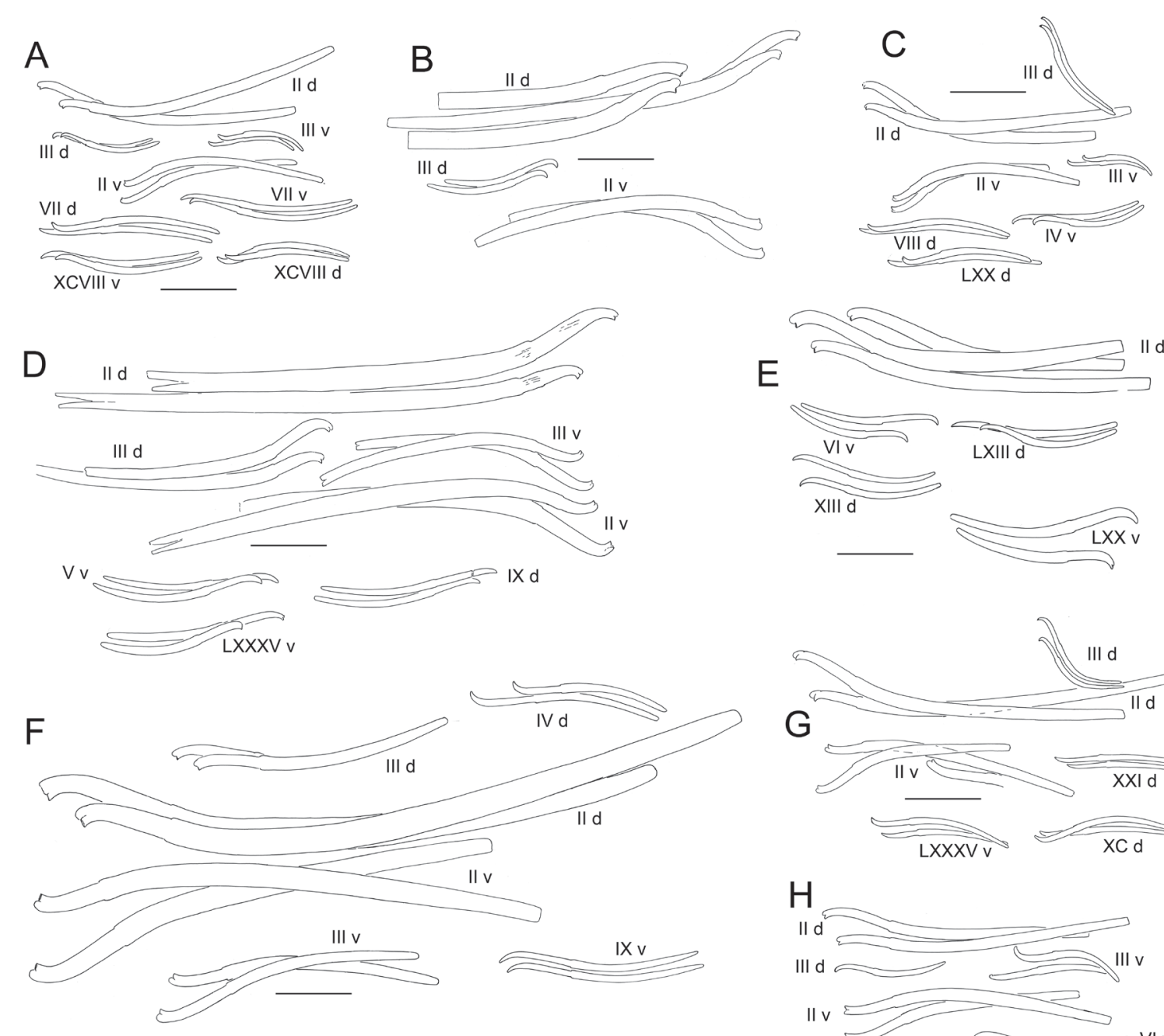

$\mathrm{E}$
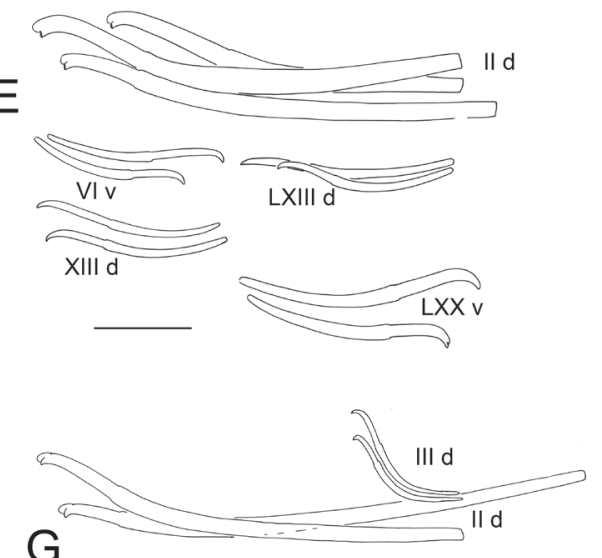

G
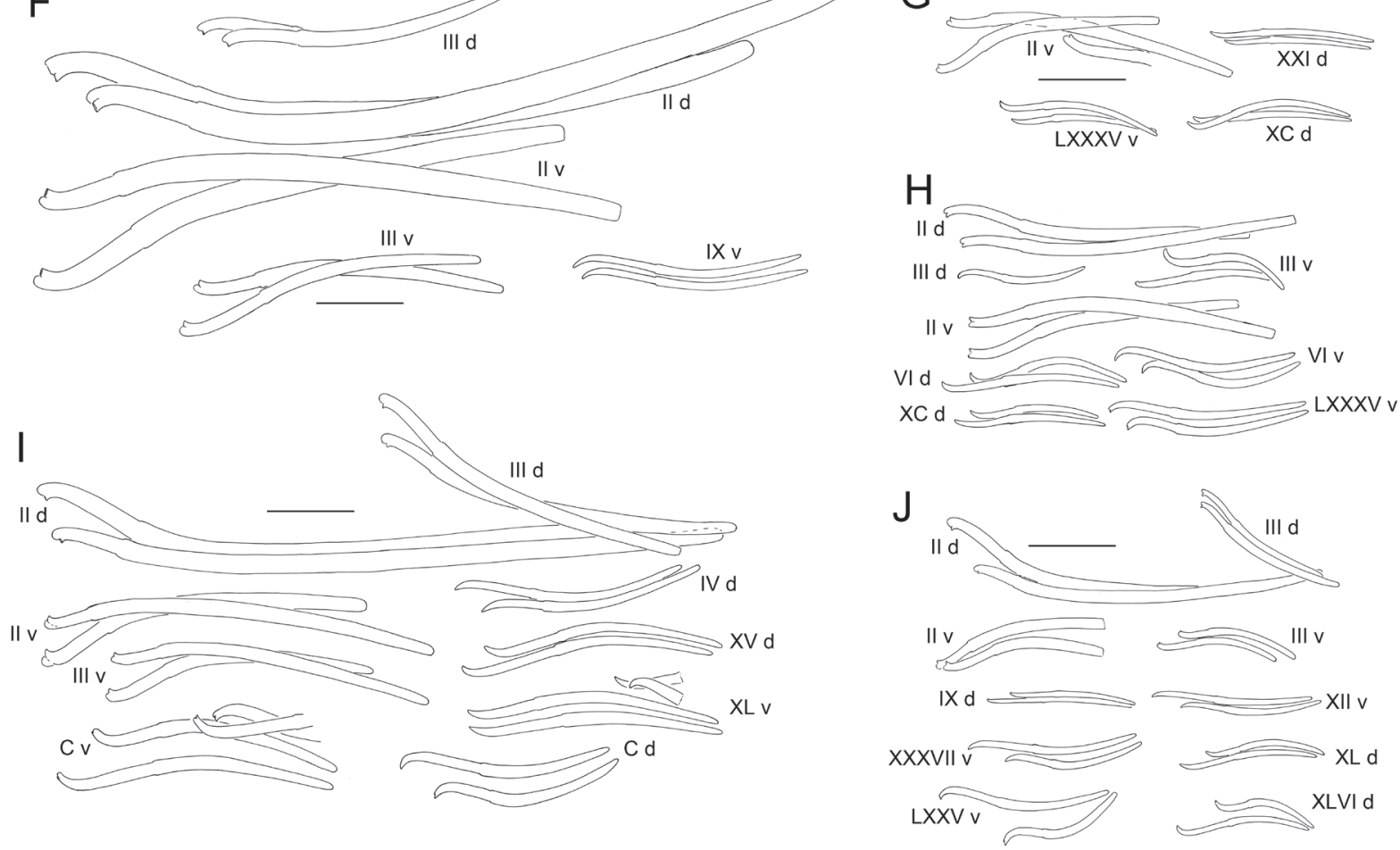

Fig. 10. Guestphalinus elephantinus Fend \& Rodriguez sp. nov., various sites, arranged approximately north-south; paired chaetae; $\mathrm{d}=$ dorsal bundle, $\mathrm{v}=$ ventral. A. From Shale Creek, WA (type locality). B-C. From Clearwater River, WA; C shows II and III in relative positions at top. D. West Fork Satsop River, WA. E. Tucannon River, WA; II dorsal bundle with 1 replacement chaeta. F. Euchre Creek, OR. G. Mule Creek at Rogue River, OR; II and III dorsal are shown in relative positions. H. Spring at Peavine Ridge, OR. I-J. A mature and immature worm from Guadalupe Creek, CA; II and III shown in relative positions; XL ventral and C ventral in I have partially-developed replacements; II ventral chaetae partially-developed in J. Scale bars: $100 \mu \mathrm{m}$. 

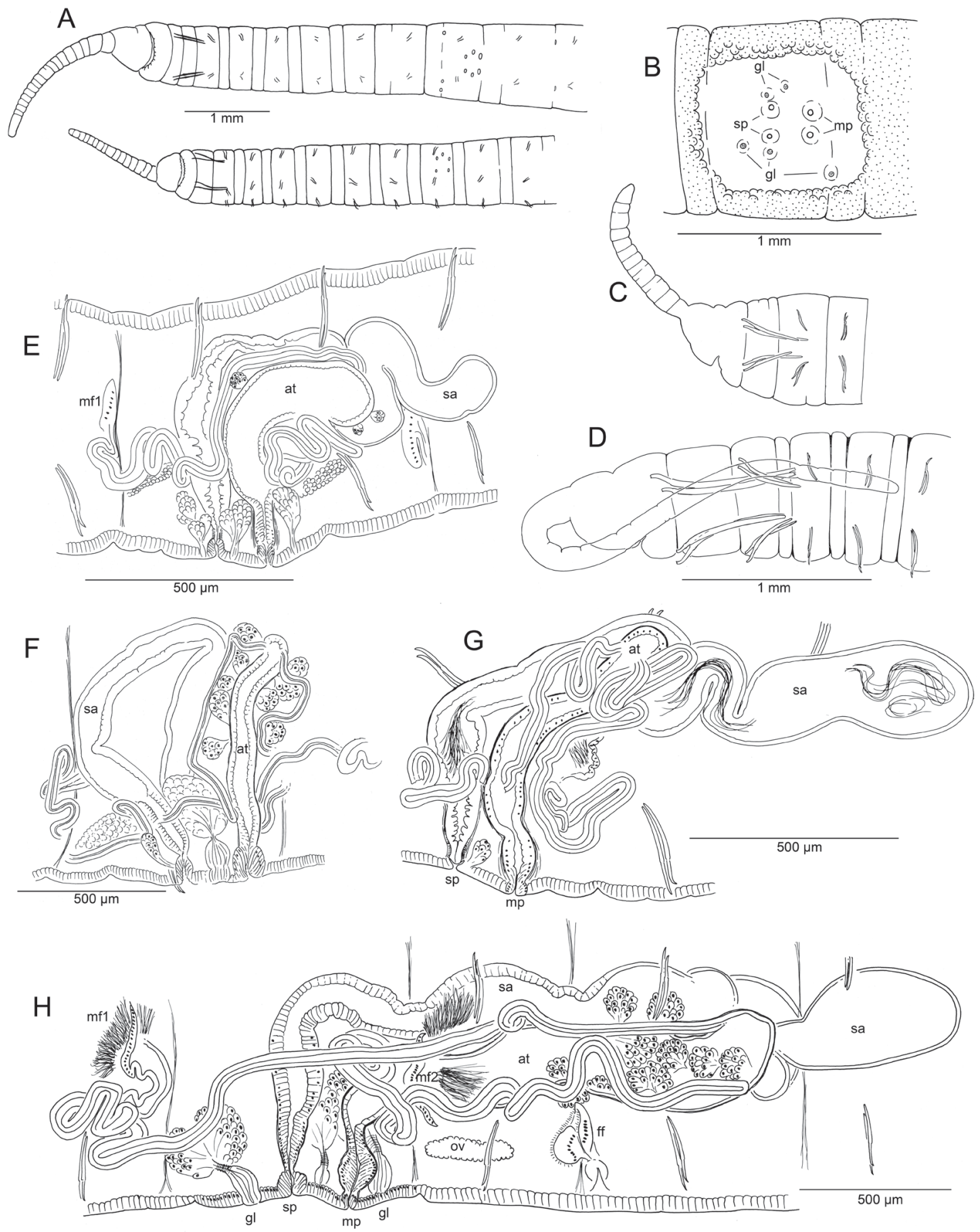

Fig. 11. Guestphalinus elephantinus Fend \& Rodriguez sp. nov. A. Ventral view of two worms from Shale Creek, WA (type locality); upper drawing is the holotype, lower is a post-reproductive worm. B. Ventral view of segment IX, showing genital field of a mature worm from Guadalupe Creek, CA; secretory openings of 5 glands are visible, in addition to paired male and spermathecal pores. C. Anterior end, from Peavine Ridge spring, OR, showing position of chaetae in II-IV. D. Anterior end of worm from Middle Fork Satsop River, WA. E. Reproductive organs of a mated worm from Shale Creek (holotype). F. Segment IX of an unmated worm, Peavine Ridge. G. Atrium and spermatheca in IX of a mated, but slightly post-mature worm from Clearwater River, WA; sperm present in spermatheca, but atrium is reduced in size. H. Reproductive organs in segments VIII-XII of a mated, mature worm from Guadalupe Creek, CA. 
Chaetae in II much larger and thicker than those in posterior segments (Table 3), bifid, with a short, thick lower tooth and a larger, rounded and laterally compressed upper tooth (Figs10A-C, 12C), directed anteriorly, with proximal ends protruding into posterior segments (cf. Figs 11C-D, 12B). Dorsal chaetae in II about 30-40\% longer than those in ventral bundles (Table 3); within each bundle in II, the lateral (i.e., outer) chaeta is slightly longer, with a more distal nodulus ( 0.15 from tip, vs 0.24 in the median (inner) chaeta), and usually has a distal thickening that appears as a "secondary nodulus" between nodulus and tip (Fig. 12C-D). Chaetae in III simple-pointed or slightly bifid, and oriented more perpendicularly to body, but still facing anteriad (Figs 10C, 12B); much shorter than chaetae in II and slightly shorter than those in other segments (Table 3). Chaetae in IV and posterior segments usually oriented posteriorly, simple-pointed, sigmoid (Fig. 12H). From III to about XX, nodulus about $0.3-0.4$ from the tip, but the median (inner) chaeta in each bundle is slightly longer. In posterior segments, chaetae of similar length, but slightly thicker, and nodulus $0.25-0.35$ from the tip; simple-pointed or with a small notch or dorsal keel in tail segments. Ventral chaetae absent in IX in mature or post-mature worms.

Epidermis in anterior segments $15-20 \mu \mathrm{m}$ thick; in clitellum to $48 \mu \mathrm{m}$ in the holotype; narrower, densely packed cells up to $30 \mu \mathrm{m}$ on ventral side of IX (in area surrounding genital pores) in the holotype and in the post-reproductive worms; posteriorly $10-12 \mu \mathrm{m}$. Body-wall musculature, brain, pharynx, pharyngeal glands, nephridia, blood vessels and chloragogen as described above for G. exilis sp. nov., except that pharyngeal glands in G. elephantinus sp. nov. extend to VII in all specimens observed.

Male and spermathecal pores paired in IX. Male pores just anterior to the posterior intersegmental groove (Fig. 11A), slightly inside the line of ventral chaetae; spermathecal pores aligned with and in front of male pores, between or slightly posterior to chaetal bundles. Female pores paired, on chaetal line at 10/11; female funnel up to $130 \mu \mathrm{m}$ high (Fig. 12Q). A variable number of copulatory glands with internal structure as described for $G$. exilis sp. nov.; with round secretory openings located close to spermathecal and male pores. The mature worm (holotype) has 3 pairs of petiolate copulatory glands in IX, 100-140 $\mu \mathrm{m}$ high, lateral to, in front of, and behind genital pores (Fig. 11E), although not all of these were visible externally (Fig. 11A). Copulatory glands smaller and indistinct or absent in the postreproductive worms (male duct and spermathecae expanded; large but nearly empty sperm and egg sacs extending to XV), but faint external secretory openings visible in one specimen.

Spermathecae up to $1700 \mu \mathrm{m}$ long in the holotype; ectal $1 / 4$ is duct-like, nearly tubular (about $90 \mu \mathrm{m}$ in diameter); ental ampulla-like portion irregular, up to about $100 \mu \mathrm{m}$ in diameter, folded within $\mathrm{X}$ or extending into XI. Ectal part with irregularly columnar cells up to $35 \mu \mathrm{m}$ high, epithelium gradually becoming thinner in ental ampulla. Spermathecae end in a short, narrow constriction surrounded by a ring of muscle fibers (Fig. 11E, cf. Fig. 12L) which opens in a shallow epidermal infolding, about $40 \mu \mathrm{m}$ deep. Spermathecae of a paratype similar (Fig. 11G), 1200-2600 $\mu \mathrm{m}$ long, with loose sperm; ampulla thin-walled, ental diameter up to $230 \mu \mathrm{m}$, extending into $\mathrm{X}$ or as far as XII.

Anterior pair of male funnels on 8/9; posterior male funnels on $9 / 10$, directed back into X; male funnels of post-reproductive worms indistinct, without or with small amount of sperm. Anterior vas deferens extends into VIII (Fig. 11E), forming a compact, convoluted mass, then penetrates $8 / 9$, running along ventral body wall to near the male pore, then follows the atrium before joining the atrial wall and entering the lumen near the apex (junction not clear on holotype). Length of anterior vas deferens up to about $1500 \mu \mathrm{m}$, width of both anterior and posterior vasa deferentia 30-36 $\mu \mathrm{m}$ in the holotype. Posterior vas deferens forms a compact, convoluted mass in posterior part of IX, then follows the atrium externally before joining it near the ental end. Atria of holotype extend back into X; ectal duct (length $160 \mu \mathrm{m}$, width near midpoint 30-40 $\mu \mathrm{m}$ ) has a thick, columnar epithelium and thin muscle coat; ectal part of duct expanded to $50 \mu \mathrm{m}$, with epithelial cells directed outward. Entally, there is an abrupt transition to the sacciform atrial ampulla; ampulla length up to $550 \mu \mathrm{m}$, width up to $130 \mu \mathrm{m}$, with thin-walled 

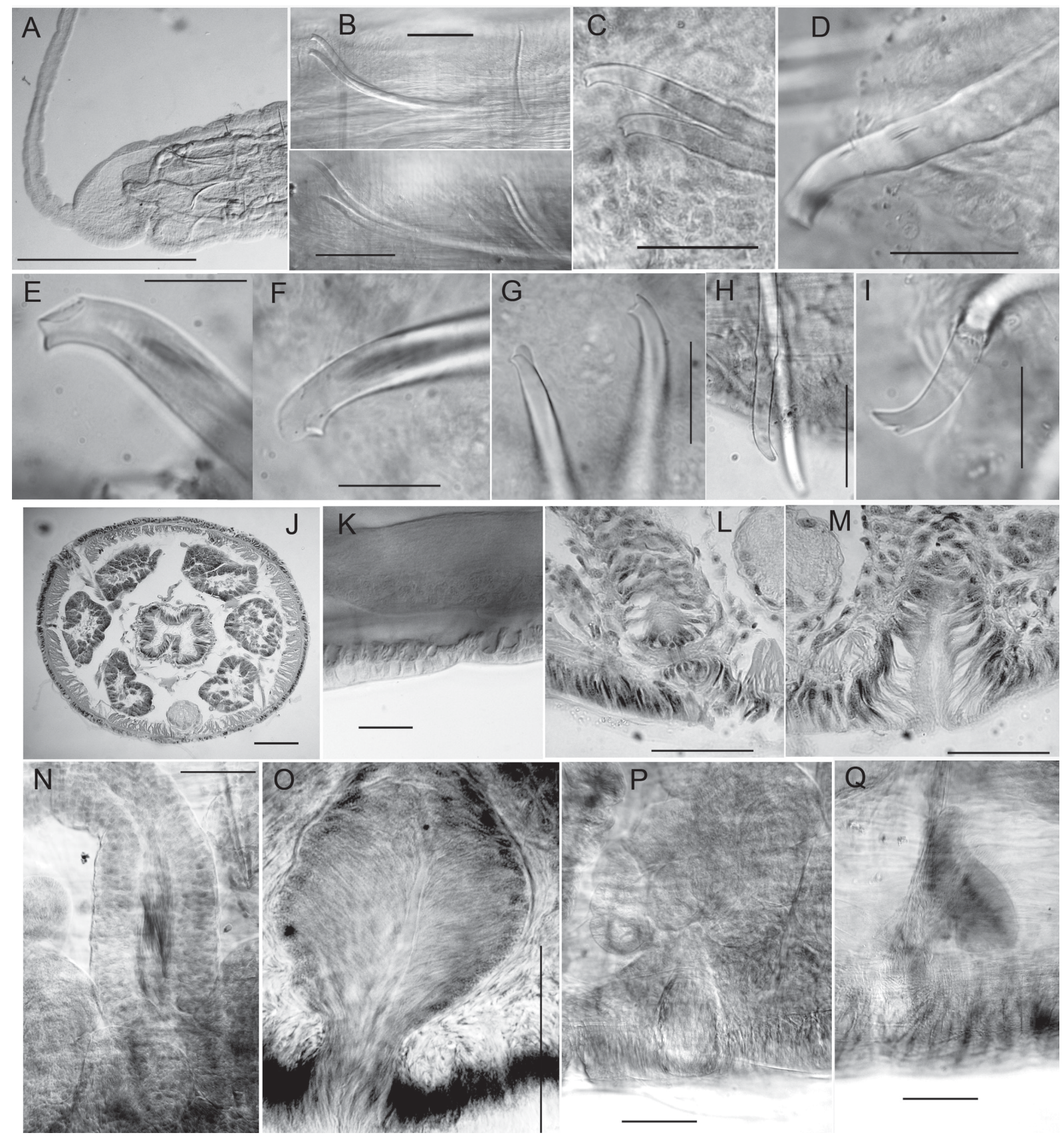

Fig. 12. Guestphalinus elephantinus Fend \& Rodriguez sp. nov. A-B (upper) from Clearwater River, WA; C, H, K from Shale Creek, WA (type locality); D-E from Satsop River, WA; B (lower), F-G, N-Q from Guadalupe Creek, CA; I-J, L-M from Peavine Ridge, OR. A. Anterior end of cleared worm. B. Chaetae in II-III, comparing worms from northern (upper) and southern (lower) populations. C. Dorsal chaetae in II. D. The outer chaeta in II, showing the "secondary nodulus". E-F. Inner dorsal chaeta in II; E shows folded keel. G. Modified dorsal chaetae in II. H. Posterior ventral chaeta. I. Posterior ventral chaeta with bifid tip. J. Transverse section of anterior segment, showing lobes of pharyngeal glands. K. Body wall in anterior segment. L. Spermathecal pore. M. Male pore. N. Ectal part of spermatheca from a dissected, mated worm. O. Expanded atrial duct (type 2 penis?) at male pore. P. Copulatory gland. Q. Female funnel and pore on intersegment 10/11. Scale bars: A $=1 \mathrm{~mm} ; \mathrm{B}-\mathrm{I}, \mathrm{K}-\mathrm{M}=50 \mu \mathrm{m} ; \mathrm{J}, \mathrm{N}-\mathrm{Q}=100 \mu \mathrm{m}$. 
epithelium and a wide lumen (Fig. 11E). Small clusters of prostatic cells, 20-40 $\mu \mathrm{m}$ high, very sparse. Atria tubular, with ampulla not expanded in a paratype (apparently at a more advanced stage of maturity, after copulation, Fig. $11 \mathrm{G}$ ); length $400-800 \mu \mathrm{m}$, diameter $60-80 \mu \mathrm{m}$; prostates very small or absent; atrial duct and male pore as in the holotype.

\section{Specimens from other localities}

Satsop River, western Washington: Modified chaetae in both II and III; chaetae in II very long (Table 3); lateral (outer) chaeta in the largest specimen with secondary nodulus, as in topotypic specimens (Fig. 12D). Chaetae in III smaller, but bifid and larger than chaetae in the next segments, and directed anteriad (Fig. 11D).

Tucannon River, eastern Washington: Typically modified chaetae in II, but without secondary nodulus; small, simple-pointed chaetae in III; ventral chaetae in posterior segments enlarged, longer and thicker than corresponding dorsals or ventrals in anterior segments posterior to III; some posterior chaetae are slightly keeled (Fig. 10E). In the unmated, nearly-mature worm, tubular spermatheca, vasa deferentia, atrium and prostates similar to those of the Peavine Ridge material (cf. Fig. 11F). Copulatory glands large, up to about $150 \mu \mathrm{m}$ high, anterolateral and posterolateral to the male pores.

Peavine Ridge, northern Oregon: Chaetae in II enlarged and modified as above, without secondary nodulus (Figs 10H, 11C); chaetae in III simple-pointed, smaller than other anterior chaetae. Posterior segments with ventral chaetae larger than dorsals; both dorsal and ventral chaetae slightly bifid or keeled (Fig. 12I). In unmated, nearly-mature worms, there is a variable number (2-4) of well-developed, petiolate copulatory glands with distinct external secretory openings, total height up to 155-290 $\mu \mathrm{m}$ (Fig.11F). Copulatory glands usually present between spermathecal and male pores (but lateral to both), other glands may be present anterior, lateral, or posterior to genital pores. Much smaller glands may insert at male and spermathecal pores. Atria and spermathecae both tubular, without sperm; male and spermathecal pores (Fig. 12L-M) as described above.

Coastal ranges, central California and southern Oregon: Highly modified chaetae in II as in typical specimens, but without secondary nodulus; the two specimens with the largest chaetae are from this region (Table 3, Fig. 10F, I). Chaetae in III also modified, shorter than those in II but similar in general form (bifid, with rounded, laterally flattened upper tooth; nodulus distal); longer than other chaetae in anterior segments (Fig. 12B, F-H). Posterior chaetae usually simple-pointed, ventral chaetae keeled in tail segments (posterior to $\mathrm{XC}$ ) of some specimens; ventrals in posterior segments larger than those in anterior segments, and larger than corresponding dorsals in some specimens.

Reproductive organs in the mature worm from Guadalupe Creek include the openings of 5 copulatory glands visible externally in IX, in ventral field, but lateral to male and spermathecal pores (Fig. 11B, H). Copulatory glands up to $250 \mu \mathrm{m}$ high; extensions of granular, petiolate cells constricted by a muscular ring, terminating in a small, external secretory opening (Fig. 12P). Clitellum from $1 / 4$ VIII through XIII. Ectal, duct-like portion of spermatheca (Figs $11 \mathrm{H}, 12 \mathrm{~N}$ ) weakly differentiated from ampulla; extending to XII, thin-walled and expanded entally. Vasa deferentia as described above (Fig. 11H), 50-60 $\mu \mathrm{m}$ wide, joining atrium subapically; histologically similar throughout, with thick, ciliated epithelium. Atria petiolate; well-defined ectal duct; ectal part of atrial duct expanded, bulbous (up to $130 \mu \mathrm{m}$ wide), with epithelial cells directed outward, possibly indicating a "type 2" penis (Fig. 12O). Sacciform atrial ampulla extending to 11/12, with thin-walled epithelium and a wide lumen (Fig. 11H); petiolate prostate glands sparsely covering ampulla. 


\section{Remarks}

All populations here attributed to G. elephantinus sp. nov. have highly modified bifid chaetae in II (or II and III), and their morphology differs from chaetae in all other lumbriculids. These anterior chaetae are distinctly enlarged, very weakly sigmoid, and anteriorly directed with a characteristic short, broad proximal tooth and a laterally-flattened distal tooth. In comparison, typical G. exilis sp. nov. have similar but only slightly modified (blunt-tipped or slightly notched) chaetae in II. Additional interpopulation variation in chaetal morphology suggests the existence of a species complex, but the rarity of mature specimens from most localities makes it difficult to compare populations with the usual morphological criteria, which focus on reproductive structures. Although our limited DNA sampling strongly supports species status for G. elephantinus sp. nov. and G. exilis sp. nov. morphotypes (see below), further molecular studies will be necessary to resolve the diversity of this genus in a region that appears to have extensive radiation within other lumbriculid genera (McKey-Fender \& Fender 2001; Fend \& Rodriguez 2003).

The morphology of modified chaetae in segment II varies among collection sites, but appears consistent within large series of immature worms collected at some of these sites. Increased chaetal size has been associated with high water conductivity in the Naididae (Loden \& Harman 1980, for Pristina aequiseta Bourne, 1891, or for Tubifex tubifex var. grandiseta Rodriguez, 1986). This does not appear to be the case for $G$. elephantinus sp. nov., since populations with very enlarged chaetae inhabit streams with a wide range of conductivity $\left(<100\right.$ to $\left.>400 \mu \mathrm{S} \mathrm{cm}^{-1}\right)$. The other western Nearctic species, G. exilis sp. nov., with much less-enlarged anterior chaetae, was collected from streams with intermediate conductivity values (ca 200-300 $\mu \mathrm{S} \mathrm{cm}^{-1}$, see G. exilis sp. nov. habitat notes, above).

The reproductive organs of G. exilis sp. nov. and G. elephantinus sp. nov. appear similar, although the morphology of these structures is difficult to define, as it varies with stage of development. Although atrial morphology is commonly used in defining lumbriculid species, it has been shown that it can vary considerably over the reproductive period in Stylodrilus mollis Timm, 1998 and Trichodrilus seirei Timm, 1979. The thin-walled, sacciform atrial ampulla in some mated specimens of both Nearctic species of Guestphalinus appears to be an unusual character for the Lumbriculidae. Unmated, mature worms (Fig. 11F) have tubular atria with a thick epithelium, whereas sac-like atria with thin walls lacking a glandular epithelium or an obvious muscle layer were observed in worms at a more advanced stage of maturity (Fig. 11E, H), including post-reproductive specimens with partially-resorbed reproductive organs.

\section{Habitat}

All sites except the spring on Peavine Ridge were alluviated streams with gravel to cobble substrate. All appear to have permanent flow, except for Guadalupe and Alamitos Creeks, where surface flow may disappear during summer months. Worms were typically collected by digging at least $20 \mathrm{~cm}$ deep in patches of finer gravel.

The Clearwater drainage sites, on the Olympic Peninsula, northwestern Washington, are larger streams in a watershed dominated by commercial forest, but with riparian buffers. These streams support populations of several salmonid species (Harrington 2005). Limited available water quality data for the Clearwater River near Clearwater (NWIS 2016b) indicate low specific conductance (measured in 19721974: 13-94 $\mu \mathrm{S} \mathrm{cm}^{-1}$ ). Guadalupe, Alamitos and Euchre Creeks are small, coastal drainages ranging from southern Oregon to central California. The Peavine Ridge collection was from an isolated springfed, seasonally inundated pool with fine sediment, and the species was found on only one of several visits. Values for specific conductance in both the Peavine Ridge spring and in Euchre Creek (measured in April 2014: 95 and $63 \mu \mathrm{S} \mathrm{cm}^{-1}$, respectively) were low. However, values tend to be much higher (at 
summer base flow, 340-490 $\mu \mathrm{S} \mathrm{cm}^{-1}$ ) in Guadalupe and Alamitos Creeks (unpublished field data, J.L. Carter, US Geological Survey, 3 sampling dates in May, June, September 1997-1998).

\section{Molecular phylogeny and genetic distances}

Two species of Kincaidiana, the two Nearctic species of Guestphalinus and Uktena riparia form a clade with high support: BA posterior probability $(\mathrm{BA} \mathrm{pp})=0.99$, bootstrap value under ML (ML bs) $=87$ in the consensus tree based on concatenated sequence data (COI, 16S rRNA and 28S rRNA) (Fig. 13). Uktena riparia is the sister species to the clade formed by Kincaidiana and Guestphalinus species in the ML tree (not shown); however, in the BA tree (Fig. 13), U. riparia is the sister species to the Kincaidiana species (BA pp $=0.88$ ), with Guestphalinus as the sister group to Kincaidiana + Uktena. Resolving the phylogenetic relationships among these 3 genera needs further molecular work; however, their relatedness is well supported by morphological evidence (see Discussion).

Together, $K$. hexatheca and $K$. smithi sp. nov. form a strongly supported clade (BA pp $=1.00$, ML bs $=$ 100 ). The two specimens of $K$. hexatheca group together (despite morphological differences, already mentioned above), and they are separated from $K$. smithi sp. nov. The uncorrected (p) distance between the two specimens of $K$. hexatheca is $3 \%$ for COI, and $7.9-8.5 \%$ between $K$. hexatheca and $K$. smithi sp. nov.; these values are concordant with intra- and interspecific values for COI found in other lumbriculids (Achurra \& Erséus 2013; Achurra et al. 2015). Note that the type locality of K. smithi sp. nov. (on the Smith River) is geographically located between the localities of the two sequenced specimens of $K$. hexatheca, and the closest of the latter to the Smith River (Cow Creek, about $150 \mathrm{~km}$ to the north) corresponds to the lowest genetic distance (7.9\%). For Clitellata, Erséus \& Gustafsson (2009) proposed distances of $10 \%$ or more for congeneric species; distances of about $5 \%$ were interpreted as

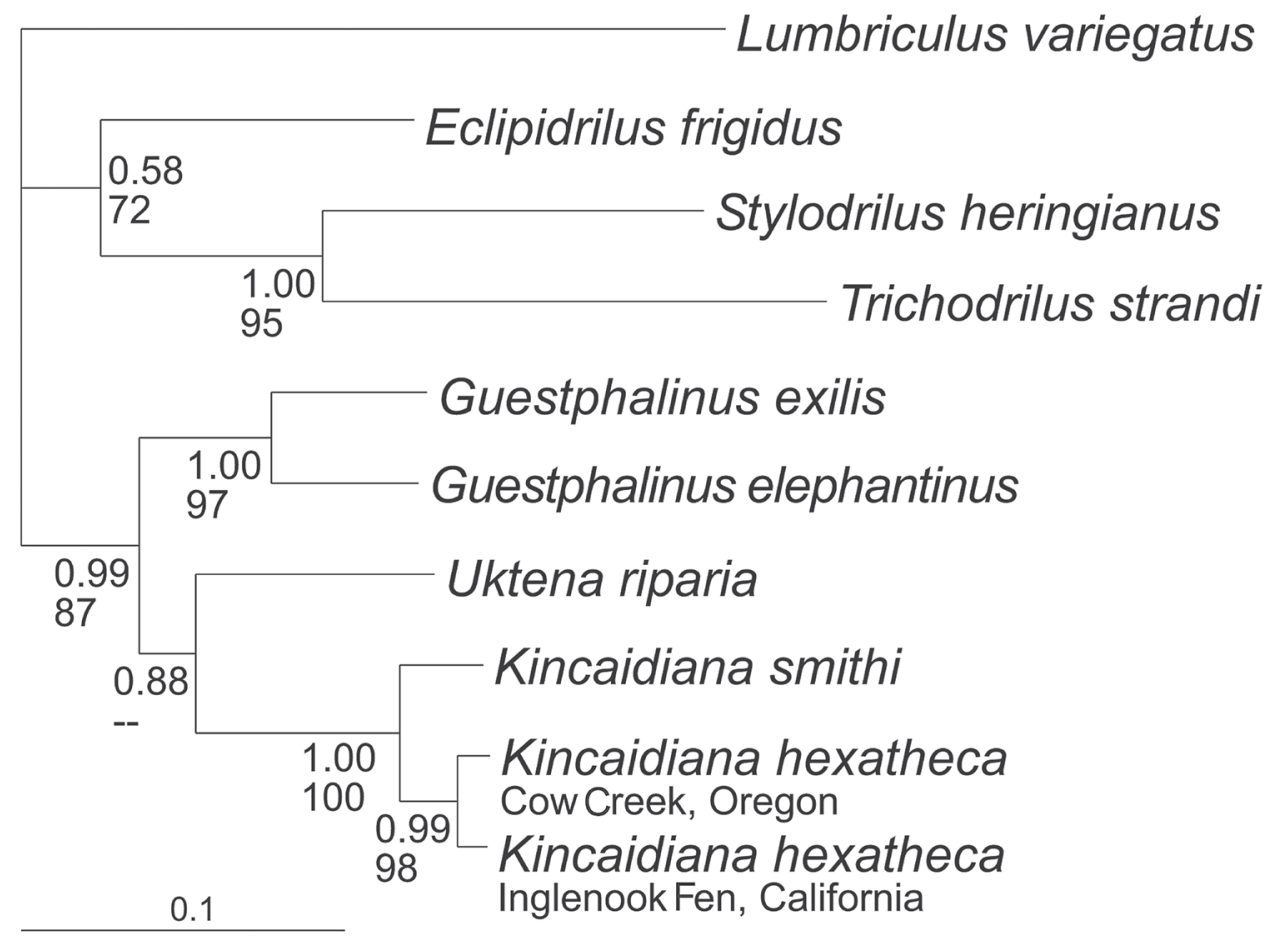

Fig. 13. BA consensus tree derived from the concatenated sequences of COI, $16 \mathrm{~S}$ rRNA and 28S rRNA genes. Numbers beside internal branches indicate BA posterior probabilities $(\geq 0.90)$ and ML bootstrap values $(\geq 70 \%)$. The geographical location for two specimens of $K$. hexatheca Altman, 1936 is given under the taxon name. 
due to putative ongoing speciation (Zhou et al. 2010), which could be the case for the Kincaidiana species under study.

Guestphalinus exilis sp. nov. and G. elephantinus sp. nov. group together with high support (BA pp = 1.00 , ML bs $=97$ ), having an uncorrected (p) distance of $13.2 \%$ for COI; this value is high and together with the morphological differences (mainly based on chaetae, see above) supports the recognition of two distinct species.

\section{Discussion}

Both morphology and DNA suggest that Kincaidiana, Guestphalinus and Uktena are phylogenetically related. With respect to morphology, the three genera share several distinctive, and probably synapomorphic characters: an elongate-filiform proboscis, spermathecae in the atrial segment, male ducts and pores in a segment anterior to $\mathrm{X}$, and elongate or tubular atria and spermathecae.

The filiform proboscis appears superficially ringed in preserved specimens of all three genera, and was referred to as "pseudo-segmented" by Cook (1971) for K. hexatheca, as rings are not associated with septa. Other lumbriculid taxa, Rhynchelmis, Eclipidrilus (Premnodrilus) and Eremidrilus, are also characterized by an elongate, although usually shorter proboscis, and surface wrinkling (which may appear as rings) varies with fixation.

Most other lumbriculid genera have the spermathecae in either pre- or post-atrial segments, and only the three Cookidrilus species have paired spermathecae in the atrial segment. Two species of Dorydrilus (D. michaelseni Piguet, 1913 and D. tetrathecus Hrabě, 1960) also have spermathecae in the atrial segment. Dorydrilus is generally placed in the Dorydrilidae, although sometimes assigned to the Lumbriculidae (e.g., Hrabě 1983). Cookidrilus and Dorydrilus are small worms, without a proboscis, and also differ from Kincaidiana, Guestphalinus or Uktena in most other respects.

The position of the male pores in VIII (Uktena) or IX (Kincaidiana and Guestphalinus) likely represents a forward shift from an ancestral position in X (Brinkhurst 1989). A forward shift in the position of reproductive organs is known in both semiprosoporous (particularly the Trichodrilus group having bifid chaetae: T. strandi Hrabě, 1936, T. diversisetosus Rodriguez, 1986, T. campoyi Rodriguez, 1988 and T. isabellae Popchenko, 1988) and prosoporous lumbriculids (e.g., Altmanella).

The general form of the elongate spermathecae and atria is similar in Kincaidiana, Guestphalinus and Uktena. In most cases, the ectal, duct-like section of the spermatheca widens gradually to form an elongate, sacciform (irregular) ampulla, and in both Kincaidiana and Guestphalinus the spermathecae terminate in a muscular sphincter just before the pore. As in some other lumbriculids having elongate spermathecae (e.g., some Rhynchelmis (Rhynchelmoides) and Pilaridrilus Fend \& Lenat, 2007), dense accumulations of sperm are also lined up along an ectal region with more columnar epithelium, and more diffuse sperm is present in the ampulla (Fend \& Lenat 2007, 2010).

\section{Chaetae}

Apart from the occurrence of modified genital chaetae in a few species (e.g., U. riparia and four species of Pseudorhynchelmis Hrabě, 1982; Martin \& Kaygorodova 2008), most lumbriculids have rather uniform, sigmoid chaetae with a nodulus somewhat distal to the midpoint. Simple-pointed chaetae are most common in the family, although bifid somatic chaetae occur as intra-generic variation in several lumbriculid genera (e.g., Stylodrilus, Rhynchelmis, Lumbriculus) as well as in the monotypic Wsewolodus Semernoy, 2004. Bifid chaetae in those taxa have a typical lumbriculid form, with a small, thin upper tooth; furthermore, bifids occur throughout the worm, or if variable, teeth are usually more developed 
in posterior segments. Chaetal differences among body regions are usually minor, and limited to greater size of ventrals vs dorsals, or a gradual decrease in size along the body axis. Ventral chaetae may be larger than dorsals in some species of several lumbriculid genera, e.g., Stylodrilus mirus (Cekanovskaya, 1956), Lamprodrilus mrazeki Hrabě, 1928, Sylphella puccoon Rodriguez et al., 2014 and Trichodrilus diversisetosus Rodriguez, 1986. The strongly hooked dorsal chaetae of the predaceous Phagodrilus McKey-Fender, 1988 are developed only in posterior segments. Other unusual chaetal modifications, such as elongate distal ends of dorsal chaetae in Trichodrilus capilliformis Giani \& Rodriguez, 1994 and Stylodrilus wahkeenensis Rodriguez \& Coates, 1996, the elongated ventral chaetae of Lamprodrilus bythius Michaelsen, 1905 and some Rhynchelmis rostrata (Eisen, 1888) (Fend \& Brinkhurst 2000), or the partial or complete loss of chaetae in some species of Lamprodrilus (e.g., L. achaetus Isossimov, 1962) could also be interpreted as derived characters related to a particular lifestyle.

Some anterior chaetae are distinctly modified in both Kincaidiana and the Nearctic Guestphalinus; they may appear larger and bifid or even trifid in lateral view, and where most developed, modified chaetae in both taxa show a flattened, dorsal keel. The wide range in size or degree of modification among populations in these taxa suggest local speciation and perhaps adaptation to different external conditions (e.g., sediment particle size distribution). In both Kincaidiana and G. elephantinus sp. nov., the forward orientation of the enlarged and modified anterior chaetae suggests a particular mechanical adaptation to locomotion or feeding (including the possibility of predatory behavior).

The inconspicuous dorsal keel at the tip of posterior chaetae in some specimens of Kincaidiana and the Nearctic species of Guestphalinus has not been reported in other lumbriculids, and the grooved tips on posterior chaetae of one specimen of $G$. wiardi also appear unusual. Nevertheless, similar chaetae with keeled tips have been described in unrelated taxa, e.g., two species in the family Haplotaxidae: Delaya leruthi (Hrabě, 1958) (Delay 1972: figs 1-2) and D. navarrensis (Delay, 1973) (Delay 1973: fig. 1).

\section{Male ducts}

Guestphalinus has a semiprosoporous male duct (with 2 male ducts per atrium), in contrast to the prosoporous ducts of the related Kincaidiana and Uktena. Although this has been considered a phylogenetically important character, it is likely that a reduction of the anterior vas deferens has occurred more than once in lumbriculids (see Brinkhurst 1989).

Both of our specimens of $G$. wiardi and the description by Michaelsen (1933: fig. 2) indicate that the anterior vasa deferentia form a loop in the pre-atrial segment, as in G. exilis sp. nov. and G. elephantinus sp. nov. This character has not been reported in other Lumbriculidae so far. Hrabě (1984) considered the penetration of the posterior septum by the posterior vas deferens in semiprosoporous lumbriculids to be an atavistic character, associated with the loss of the posterior pair of atria from a double-pair of prosoporous atria; following that logic, this new structure could suggest the loss of an anterior atrium. The male funnels extend several segments back within posterior sperm sacs in Kincaidiana, Uktena, and possibly in some G. wiardi (Michaelsen 1933: fig. 2; but not confirmed in our material); this character is also somewhat unusual in the family, even in genera having very elongate atria (e.g., Rhynchelmis and Eclipidrilus).

\section{Copulatory glands}

Large, stalked glands (Pubertätsdrüsen in Michaelsen 1933), are associated with the male and/ or spermathecal pores in Guestphalinus. The glands have a similar structure in all species, with cell extensions passing through a narrow muscular constriction and terminating in small, circular secretory openings in the epidermis. These glands are here regarded as probable copulatory glands, as they are well developed in both nearly-mature (unmated) and mature worms, often smaller in post-copulatory worms with well-developed eggs, and disappear in post-reproductive worms. Species of Kincaidiana have well-defined penes, the most common condition in Lumbriculidae, but the absence of this efficient 
means of sperm transfer in Guestphalinus further suggests that the glands in the ventral region (close to the genital pores) are associated with mating. Large glands of this form also occur in Uktena riparia Fend et al., 2015, where they probably have some function in the transfer of spermatophores, but, instead of opening externally, these open within the complex spermathecal and male bursae.

Glands of this form are uncommon in the Lumbriculidae, but similar structures, with external openings in (or just behind) the male segment, have been described in Rhynchelmis brooksi Holmquist, 1976 and some species of Lamprodrilus (e.g., Isossimov 1962: figs 14, 28), where they have been termed "accessory copulatory glands" (Cook 1971; Michaelsen 1901). Midventral glands with a similar form have also been described in anterior segments of sexually mature specimens of some species of Rhynchelmis (Rhynchelmoides) (Holmquist 1976; Fend \& Brinkhurst 2000, 2010). All of the above glands lack a distinct duct, and the conjoined ends of the gland cells open via a small secretory surface. Members of other oligochaete families (e.g., Naididae, Enchytraeidae, Haplotaxidae) have similar glands opening externally near the genital pores at maturity, in some cases associated with genital chaetae (e.g., Rodriguez \& Fend 2013); their sporadic occurrence in different lineages suggests that they are convergent.

Glands associated with reproductive structures in some other lumbriculid genera differ in structure. More elaborate, glandular "Kopulationsdrüsen" (e.g., Michaelsen 1901), or "accessory organs" (Fend \& Brinkhurst 2010) occur in some Rhynchemis (Rhynchelmis) species. These organs have an internal lumen, opening through a duct into a simple pore, and have been considered to be rudimentary atria. Michaelsen considered the glands in G. wiardi as possible "Geschlechtsborstendrüsen", similar to glands associated with copulatory chaetae in other microdriles, but he was unable to associate them with the ventral chaetae. Although common in other microdrile families, glands associated with genital chaetae are rare within the Lumbriculidae, and have only been described in detail for some species of Pseudorhynchelmis Hrabě, 1982 (Martin \& Kaygorodova 2008).

\section{Conclusions}

Morphology (proboscis, spermathecae in the atrial segment, and general morphology of reproductive organs) suggests that Kincaidiana, Guestphalinus and Uktena are phylogenetically related. This relationship is confirmed by the molecular data available at this time: the three genera form a strongly supported clade in the tree topology (Fig. 13), based on a limited set of lumbriculid outgroup taxa. At this point, it should be noted that no molecular phylogeny of the family Lumbriculidae as a whole has been published. Further molecular analyses, including more genera, are clearly a priority for any understanding of relationships within the family.

Populations of both Kincaidiana and Guestphalinus are quite variable across their distributions in western North America. Our DNA results provide good confirmation that the two most distinctive populations, $K$. smithi sp. nov. (with a single median atrium) and G. exilis sp. nov. (with only slightly modified anterior chaetae), are closely related to their more widespread congeners, $K$. hexatheca (with paired atria) and G. elephantinus sp. nov. (with highly modified anterior chaetae), yet differ by interspecific COI distances of $8 \%$ or more. Still, given the geographic variation in morphological characters in Nearctic populations of Kincaidiana and Guestphalinus, further molecular analyses among and within populations would also be of interest, and could provide evidence of speciation processes in the region. Finally, behavioral observations, including the feeding behavior of Kincaidiana and Guestphalinus, may eventually reveal the function of modified chaetae.

\section{Acknowledgements}

Ralph Brinkhurst, Mark Wetzel and two anonymous reviewers provided detailed and constructive reviews of the manuscript. We greatly appreciate the access to specimens of Kincaidiana hexatheca provided by Bob Wisseman (Aquatic Biology Associates, Corvallis, Oregon) and to the type material 
provided by Rod Crawford (Burke Museum, Seattle, Washington). Renee Pasquinelli (California State Parks) assisted with the permit for collecting $K$. hexatheca at Inglenook Fen. Petr Dolejš (Czech National Museum, Prague) located the significant Guestphalinus wiardi specimen from the Hrabě collection. The Italian specimen of G. wiardi (collected by S. Dattagupta and J.L. Macalady) was kindly provided by Alessandro Montanari (Osservatorio Geologico di Coldigioco, Frontale de Apiro, Italy). Uttam Rai (Rhithron Associates, Missoula, Montana) expanded the known range of G. elephantinus sp. nov. with specimens from eastern Washington and Wayne Fields (Hydrozoology, Newcastle, California) found the Garcia River specimen of G. exilis sp. nov. Dr. Ainara Achurra had a PostDoc position, financed by the Basque Government (Programa Postdoctoral de Perfeccionamiento) in 2013-2015 that partly financed her contribution to this paper. Any use of trade, firm or product names is for descriptive purposes only and does not imply endorsement by the U.S. Government.

\section{References}

Achurra A. \& Erséus C. 2013. DNA barcoding and species delimitation: the Stylodrilus heringianus case (Annelida : Clitellata : Lumbriculidae). Invertebrate Systematics 27: 118-128.

https://doi.org/10.1071/IS12049

Achurra A., Rodriguez P. \& Erséus C. 2015. Pseudo-cryptic speciation in the subterranean medium: a new species of Stylodrilus Claparède, 1862, with a revision of the status of Bichaeta Bretscher, 1900 (Annelida, Clitellata, Lumbriculidae). Zoologischer Anzeiger 257: 71-86.

https://doi.org/10.1016/j.jcz.2015.05.003

Alfaro M.E., Zoller S. \& Lutzoni F. 2003. Bayes or bootstrap? A simulation study comparing the performance of Bayesian Markov chain Monte Carlo sampling and bootstrapping in assessing phylogenetic confidence. Molecular Biology and Evolution 20: 255-266.

https://doi.org/10.1093/molbev/msg028

Altman L.C. 1936. Oligochaeta of Washington. University of Washington Publications in Biology 4: 1-137.

Bely A.E. \& Wray G.A. 2004. Molecular phylogeny of naidid worms (Annelida: Clitellata) based on cytochrome oxidase I. Molecular Phylogenetics and Evolution 30: 50-63.

https://doi.org/10.1016/S1055-7903(03)00180-5

Brinkhurst R.O. 1976. Aquatic Oligochaeta Recorded from Canada and the St. Lawrence Great Lakes. Institute of Ocean Sciences, Patricia Bay, Victoria, British Columbia.

Brinkhurst R.O. 1989. A phylogenetic analysis of the Lumbriculidae (Annelida, Oligochaeta). Canadian Journal of Zoology 67: 2731-2739. https://doi.org/10.1139/z89-387

Brinkhurst R.O. 1998. On the genus Eclipidrilus Eisen, 1881 (Lumbriculidae, Clitellata), including a description of Eclipidrilus ithys sp. nov. Canadian Journal of Zoology 76: 644-659. https://doi.org/10.1139/z97-224

Brinkhurst R.O. \& Cook D.G. 1966. Studies on the North American aquatic Oligochaeta III: Lumbriculidae and additional notes and records of other families. Proceedings of the Academy of Natural Sciences of Philadelphia 118: 1-33.

Cook D.G. 1968. The genera of the family Lumbriculidae and the genus Dorydrilus (Annelida, Oligochaeta). Journal of Zoology 156: 273-289.

https://doi.org/10.1111/j.1469-7998.1968.tb04352.x

Cook D.G. 1971. Family Lumbriculidae. In: Brinkhurst R.O. \& Jamieson B.G.M. (eds) Aquatic Oligochaeta of the World: 200-285. University of Toronto Press, Toronto. 
Dayrat B., Tillier A., Lecointre G. \& Tillier S. 2001. New clades of euthyneuran gastropods (Mollusca) from 28S rRNA sequences. Molecular Phylogenetics and Evolution 19: 225-235. https://doi.org/10.1006/mpev.2001.0926

Delay B. 1972. Un nouvel oligochète Haplotaxidae souterrain des Pyrénées-Orientales (France): Haplotaxis corbarensis n. sp. Annales de Spéléologie 27: 329-340.

Delay B. 1973. Deux nouveaux Oligochètes Haplotaxidae troglobies d'Espagne: Haplotaxis navarrensis n. sp. et Haplotaxis cantabronensis n. sp. Annales de Spéléologie 28: 405-411.

Dembitsky E.B. 1987. Novyj rod vod nyh maloščetinkovyh červej v faune Sovetskogo Sojuza. In: Kačalova O.L. \& Parele E.A. (eds) Vodnye Maloščetinkovye Červi. Materialy Šestogo Vsesojuznogo Simpoziuma, Salaspils 27-30 Aprelja 1987, Riga: 12-16. [In Russian: A new genus of oligochaetes in fauna of the Soviet Union. In: Kačalova O.L. \& Parele E.A. (eds) Aquatic Oligochaeta, Materials of the 6th Symposium, Salaspils, 27-30 April 1987].

Erséus C. \& Gustafsson D. 2009. Cryptic speciation in clitellate model organisms. In: Shain D. (ed.) Annelids in Modern Biology: 31-46. John Wiley and Sons, Hoboken, NJ, USA.

https://doi.org/10.1002/9780470455203.ch3

Fend S.V. 2005. A review of the genus Eclipidrilus (Annelida: Clitellata: Lumbriculidae), with description of a new species from western North America. Zootaxa 969: 1-42.

https://doi.org/10.11646/zootaxa.969.1.1

Fend S.V. 2009. An evaluation of the genus Kincaidiana Altman, 1936, with the designation of Altmanella n. gen. (Annelida, Clitellata, Lumbriculidae). Zootaxa 2077: 1-30.

Fend S.V. \& Brinkhurst R.O. 2000. New species of Rhynchelmis (Clitellata, Lumbriculidae), with observations on the Nearctic species. Hydrobiologia: 428: 1-59. https://doi.org/10.1023/A:1003919312142

Fend S.V. \& Brinkhurst R.O. 2010. Contributions towards a review of the genus Rhynchelmis Hoffmeister (Clitellata: Lumbriculidae). Zootaxa 2407: 1-27. https://doi.org/10.5281/zenodo.194252

Fend S.V. \& Lenat D.R. 2007. Two new genera of Lumbriculidae (Annelida, Clitellata) from North Carolina, USA. Zootaxa 1666: 1-22. https://doi.org/10.5281/zenodo.180092

Fend S.V. \& Lenat D.R. 2010. New southeastern Nearctic Rhynchelmis (Rhynchelmoides) species and the description of Pararhynchelmis n. gen. (Annelida: Clitellata: Lumbriculidae). Zootaxa 2554: 1-22. https://doi.org/10.5281/zenodo.196882

Fend S.V. \& Lenat D.R. 2012. New Eclipidrilus species (Annelida, Clitellata, Lumbriculidae) from southeastern North America. Zootaxa 3194: 51-67. https://doi.org/10.5281/zenodo.210008

Fend S.V. \& Ohtaka A. 2004. Yamaguchia toyensis n. sp., n. gen. (Annelida, Clitellata, Lumbriculidae) from profundal lake habitat in Japan. Zoological Science 21: 677-683. https://doi.org/10.2108/zsj.21.677

Fend S.V. \& Rodriguez P. 2003. Eremidrilus n. gen. (Annelida, Clitellata, Lumbriculidae) and new species from California, U.S.A. Canadian Journal of Zoology 81: 515-542.

https://doi.org/10.1139/z02-235

Fend S.V., Rodriguez P. \& Lenat D.R. 2015. Uktena riparia n. gen., n. sp. (Annelida, Clitellata, Lumbriculidae), a new spermatophore-producing oligochaete. Zootaxa 3994 (3): 411-424.

https://doi.org/10.11646/zootaxa.3994.3.5

Folmer O., Black M., Hoeh W., Lutz R. \& Vrijenhoek R. 1994. DNA primers for amplification of mitochondrial cytochrome $c$ oxidase subunit I from diverse metazoan invertebrates. Molecular Marine Biology and Biotechnology 3 (5): 294-299.

Griepenburg W. 1941. Ein Beitrag zur Kenntnis der Wurmfauna der westfälischen Höhlen. Decheniana 100B: 73-116. 
Harrington N. 2005. Jefferson County Shoreline Master Program Update: Shoreline Inventory and Analysis. Jefferson County Department of Community Development, Port Townsend, WA.

Hillis D.M. \& Bull J.J. 1993. An empirical test of bootstrapping as a method for assessing confidence in phylogenetic analysis. Systematic Biology 42: 182-192. https://doi.org/10.1093/sysbio/42.2.182

Holmquist C. 1976. Lumbriculids (Oligochaeta) of northern Alaska and Northwestern Canada. Zoologische Jahrbücher für Systematik, Ökologie und Geografie der Tiere 103: 377-431.

Hrabě S. 1936. Über Dorydrilus (Piguetia) mirabilis n. subgen., n. sp. aus einem Sodbrunnen in der Umgebung von Basel sowie über Dorydrilus (Dorydrilus) michaelseni Pig. und Bichaeta sanguinea Bret. Spisy vydávané prírodovědeckou fakultou Masarykovy University [Aus dem Zoologischen Institut der Masaryk-Universität in Brno] 227: 3-18.

Hrabě S. 1973. On a collection of Oligochaeta from various parts of Yugoslavia. Biloški vestnik Ljubljana 21: 39-50.

Hrabě S. 1983. Evolution of the family Lumbriculidae. Note on the classification of the class Oligochaeta. Hydrobiologia 102: 171-173. https://doi.org/10.1007/BF00006344

Hrabě S. 1984. Two atavistic characters of some Lumbriculidae and their importance for the classification of Oligochaeta. Hydrobiologia 115: 15-17. https://doi.org/10.1007/BF00027887

Isossimov V.V. 1962. The oligochaetes of the family Lumbriculidae of Lake Baikal [Maloshchetinkovye chervi semeystva Lumbriculidae]. Trudy Limnologicheskogo Instituta 1 (21), part I: 3-126. [In Russian.]

Kathman R.D. \& Brinkhurst R.O. 1998. Guide to the Freshwater Oligochaetes of North America. Aquatic Resources Center, College Grove, TN.

Larkin M.A., Blackshields G., Brown N.P., Chenna R., McGettigan P.A., McWilliam H., Valentin F., Wallace I.M., Wilm A., Lopez R., Thompson J.D., Gibson T.J. \& Higgins D.G. 2007. Clustal W and Clustal X version 2.0. Bioinformatics 23: 2947-2948. https://doi.org/10.1093/bioinformatics/btm404

Loden M.S. \& Harman W.J. 1980. Ecophenotypic variation in setae of Naididae Oligochaeta). In: Brinkhurst R.O. \& Cook D.G. (eds) Aquatic Oligochaete Biology: 33-39. Plenum Press, New York. https://doi.org/10.1007/978-1-4613-3048-6_4

Martin P. \& Kaygorodova I. 2008. A new species of Pseudorhynchelmis Hrabě, 1982 (Clitellata: Lumbriculidae) from Lake Baikal, with re-descriptions of $P$. parva and P. olchonensis. Zootaxa 1938: 23-39. https://doi.org/10.5281/zenodo. 185000

McKey-Fender D. \& Fender W.M. 2001. Descriptions of new species of the predaceous lumbriculid Phagodrilus from western North America. Megadrilogica 8 (11): 57-81.

Michaelsen W. 1901. Oligochaeten der zoologischen Museen zu St. Petersberg und Kiev. Izvestija Imperatorskoj Akademii Nauk [Bulletin de l'Académie Impériale des Sciences de St. Pétersbourg] 15: $137-215$.

Michaelsen W. 1933. Über Höhlen Oligochäten. Mitteilungen über Höhlen- und Karstforschung, Zeitschrift des Hauptverbandes Deutscher Höhlenforscher 1: 1-19.

NWIS 2016a. USGS Surface-Water Daily Data for California. U.S. Geological Survey, National Water Information System. Available from http://waterdata.usgs.gov/ca/nwis/dv? [accessed 22 Feb. 2016].

NWIS 2016b. Water Quality Samples for Washington. U.S. Geological Survey, National Water Information System. Available from

http://nwis.waterdata.usgs.gov/wa/nwis/qwdata/?site_no=12040000\&agency_cd=USGS [accessed 30 Jan. 2016].

Nylander J.A.A. 2004. MrModeltest v2.3. Program distributed by the author. Evolutionary Biology Centre, Uppsala University. 
Palumbi S.R., Martin A., Romano S., McMillan W.O., Stice L. \& Grabowski G. 1991. The Simple Fool's Guide to PCR, Version 2.0. Department of Zoology, University of Hawaii, Honolulu.

Rambaut A., Suchard M.A., Xie D. \& Drummond A.J. 2014. Tracer v1.6. Available from http://tree.bio.ed.ac.uk/software/tracer/ [accessed 14 Sep. 2016].

Rettig S.A. \& Bortleson G.C. 1983. Limnological Study of Shasta Lake, Shasta County, California, with Emphasis on the Effests of the 1977 Drought. U.S. Geological Survey Water-Resources Investigations 82-4081. Available from https://pubs.er.usgs.gov/publication/wri824081 [accessed 19 Sep. 2017].

Rodriguez P. 1986. Nuevos resultados acerca de la fauna de oligoquetos acuáticos del País Vasco y cuenca alta del Ebro. 1. Haplotaxidae, Naididae y Tubificidae. Munibe (Ciencias Naturales) 38: 75-80.

Rodriguez P. \& Fend S.V. 2013. New species of Rhyacodrilus (Annelida: Clitellata: Rhyacodrilinae) of North America, with re-description of $R$. sodalis (Eisen, 1879). Zootaxa 3664 (1): 1-44. https://doi.org/10.11646/zootaxa.3664.1.1

Rodriguez P. \& Giani N. 1994. A preliminary review of the taxonomic characters used for the systematics of the genus Trichodrilus Claparède (Oligochaeta, Lumbriculidae). Hydrobiologia 278: 35-51. https://doi.org/10.1007/BF00142310

Rodriguez P., Fend S.V. \& Lenat D.R. 2014. Sylphella puccoon gen. n., sp. n. and two additional new species of aquatic oligochaetes (Lumbriculidae, Clitellata) from poorly-known lotic habitats in North Carolina (USA). ZooKeys 451: 1-32. https://doi.org/10.3897/zookeys.451.7304

Ronquist F. \& Huelsenbeck J.P. 2003. MrBayes 3: Bayesian phylogenetic inference under mixed models. Bioinformatics 19: 1572-1574. https://doi.org/10.1093/bioinformatics/btg180

Spencer D.R. \& Denton R.L. 2003. Aquatic Oligochaeta (Annelida: Lumbriculidae, Haplotaxidae, Naididae, Tubificidae) of Utah. Western North American Naturalist 63 (3): 343-352.

Swofford D.L. 2002. PAUP*: Phylogenetic Analysis using Parsimony (*and Other Methods) 4.0b10. Sinauer Associates, Sunderland, MA, USA.

Stamatakis A., Hoover P. \& Rougemont J. 2008. A rapid bootstrap algorithm for the RAxML webservers. Systematic Biology 57: 758-771. https://doi.org/10.1080/10635150802429642

U.S.D.A. 1999. Squaw Creek Watershed Analysis. Report, U.S. Department of Agriculture, Forest Service; Shasta-McCloud Management Unit.

Zhou H., Fend S.V., Gustafson D.L., De Wit P. \& Erséus C. 2010. Molecular phylogeny of Nearctic species of Rhynchelmis (Annelida). Zoologica Scripta 39: 378-393. https://doi.org/10.1111/j.1463-6409.2010.00429.x

Manuscript received: 6 February 2017

Manuscript accepted: 3 May 2017

Published on: 24 October 2017

Topic editor: Rudy Jocqué

Desk editor: Kristiaan Hoedemakers

Printed versions of all papers are also deposited in the libraries of the institutes that are members of the EJT consortium: Muséum national d'Histoire naturelle, Paris, France; Botanic Garden Meise, Belgium; Royal Museum for Central Africa, Tervuren, Belgium; Natural History Museum, London, United Kingdom; Royal Belgian Institute of Natural Sciences, Brussels, Belgium; Natural History Museum of Denmark, Copenhagen, Denmark; Naturalis Biodiversity Center, Leiden, the Netherlands; Museo Nacional de Ciencias Naturales-CSIC, Madrid, Spain; Real Jardín Botánico de Madrid CSIC, Spain. 
Appendix 1 (continued on next page). Locality data for collection sites (WGS84 datum). Abbreviations: $\mathrm{Rd}=$ road; $\mathrm{Cr}=$ creek; $\mathrm{R}=$ River; $\mathrm{Rv}=$ reservoir; $\mathrm{Pk}=$ park; $\mathrm{Cg}=$ campground.

\begin{tabular}{|c|c|c|c|c|c|}
\hline State & County & $\begin{array}{c}\text { River } \\
\text { Drainage }\end{array}$ & Site & $\begin{array}{c}\text { Longitude } \\
\left({ }^{\circ} \mathrm{W}\right)\end{array}$ & $\begin{array}{c}\text { Latitude } \\
\left({ }^{\circ} \mathrm{N}\right)\end{array}$ \\
\hline \multicolumn{6}{|c|}{ K. hexatheca Altman, 1936} \\
\hline WA & Jefferson & Hoh & small seep along Hoh River Rd & 124.1128 & 47.8167 \\
\hline WA & Jefferson & Hoh & Hoh River drainage, ditch by Clearwater Rd & 124.1532 & 47.7923 \\
\hline WA & Pacific & Naselle & spring on Naselle R & 123.7283 & 46.4000 \\
\hline WA & Clallam & Bogachiel & small pool along Bogachiel R on Undi Rd & 124.3499 & 47.8910 \\
\hline WA & Skamania & Columbia & Dog Cr near mouth & 121.672 & 45.712 \\
\hline OR & Multnomah & Columbia & Oneonta $\mathrm{Cr}$ near mouth & 122.0759 & 45.5905 \\
\hline OR & Tillamook & Nestucca & spring on Nestucca R, Bible Creek Rd & 123.7053 & 45.2709 \\
\hline OR & Yamhill & Nestucca & seep on east side of McGuire Rv & 123.3950 & 45.2910 \\
\hline OR & Lane & Big Creek & muddy seep at Big Cr, FR5700 & 124.1133 & 44.1736 \\
\hline OR & Lane & Willamette & Small spring at mouth of Tenmile $\mathrm{Cr}$ & 124.1083 & 44.2250 \\
\hline OR & Lane & Willamette & Marsh at base of Mt. Pisgah, near Eugene & 122.9494 & 43.9492 \\
\hline OR & Lane & McKenzie & Outflow from Leaburg fish hatchery & 122.6758 & 44.1075 \\
\hline OR & Lane & Siuslaw & Whittaker $\mathrm{Cr}$ at Siuslaw R & 123.6650 & 49.9861 \\
\hline OR & Douglas & Umpqua & Cow $\mathrm{Cr}$, tributary to Umpqua $\mathrm{R}$ & 123.4832 & 42.9122 \\
\hline OR & Douglas & Rogue & spring near Mule $\mathrm{Cr}$ & 123.7549 & 42.7846 \\
\hline OR & Josephine & Rogue & Darlingtonia bog near O'Brien & 123.7611 & 42.0333 \\
\hline OR & Josephine & Rogue & Illinois R near Sixmile Cr & 123.7681 & 42.3044 \\
\hline OR & Curry & Rogue & Rogue R at Quosatana Cg & 124.2339 & 42.4995 \\
\hline CA & Mendocino & (coastal) & Inglenook Fen at McKerricher State Pk & 123.78 & 39.52 \\
\hline \multicolumn{6}{|c|}{ K. smithi Fend \& Rodriguez sp. nov. } \\
\hline $\mathrm{CA}$ & Del Norte & Smith & Smith R below forks & 124.08973 & 41.81543 \\
\hline $\mathrm{CA}$ & Del Norte & Smith & Seep by South Fork Smith R & - & - \\
\hline \multicolumn{6}{|c|}{ G. exilis Fend \& Rodriguez sp. nov. } \\
\hline $\mathrm{CA}$ & Shasta & Sacramento & Squaw $\mathrm{Cr}$ at Chirpchatter $\mathrm{Cg}$ & 122.1169 & 40.8597 \\
\hline CA & Humboldt & Eel & South Fork Eel R at Elk Cr & 123.8472 & 40.2647 \\
\hline CA & Colusa & Sacramento & Stony $\mathrm{Cr}$ at Stonyford & 122.5514 & 39.3815 \\
\hline \multicolumn{6}{|c|}{ G. elephantinus Fend \& Rodriguez sp. nov. } \\
\hline WA & Jefferson & Queets & Shale $\mathrm{Cr}$ at Clearwater Creek Road & 124.2533 & 47.6370 \\
\hline WA & Jefferson & Queets & Clearwater R at Upper Clearwater Cg & 124.1170 & 47.6785 \\
\hline WA & Jefferson & Queets & Hurst $\mathrm{Cr}$ near Clearwater $\mathrm{R}$ & 124.2917 & 47.5734 \\
\hline WA & Jefferson & Queets & Bull Cr near Clearwater R & 124.1662 & 47.6670 \\
\hline WA & Jefferson & Queets & Clearwater R at Copper Mine Bottom Cg & 124.1996 & 47.6559 \\
\hline WA & Grays Harbor & Satsop & Middle Fork Satsop R & 123.5103 & 47.1778 \\
\hline WA & Columbia & Snake & Tucannon R below Turner Rd & 117.7524 & 46.4402 \\
\hline
\end{tabular}




\begin{tabular}{cccccc} 
OR & Yamhill & Willamette & spring at Peavine Ridge near McMinnville & 123.3807 & 45.2386 \\
OR & Curry & Rogue & Mule Cr at upstream bridge, near Rogue R & 123.8829 & 42.7220 \\
OR & Curry & Euchre Creek & Euchre Cr near mouth & 124.376 & 42.56 \\
CA & Santa Clara & Guadalupe & Guadalupe Cr above Guadalupe Rv & 121.8719 & 37.1827 \\
CA & Santa Clara & Alamitos & Alamitos Cr above Almaden Rv & 121.8389 & 37.1506 \\
\hline
\end{tabular}

